\title{
ENGAGING IN THE BEAUTIFUL STRUGGLE: INFLUENCE OF FACULTY LEARNING COMMUNITIES ON TEACHING
}

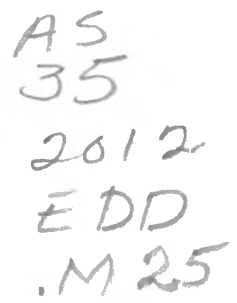

Educational Leadership

by

Savita Kumari Malik

San Francisco, California

May 2012 
Copyright by

Savita Kumari Malik

2012 


\section{CERTIFICATION OF APPROVAL}

I certify that I have read Engaging in the beautiful struggle: Influence of faculty learning communities on teaching by Savita Kumari Malik, and that in my opinion this work meets the criteria for approving a dissertation submitted in partial fulfillment of the requirements for the degree: Doctor of Education in Educational Leadership at San Francisco State University.
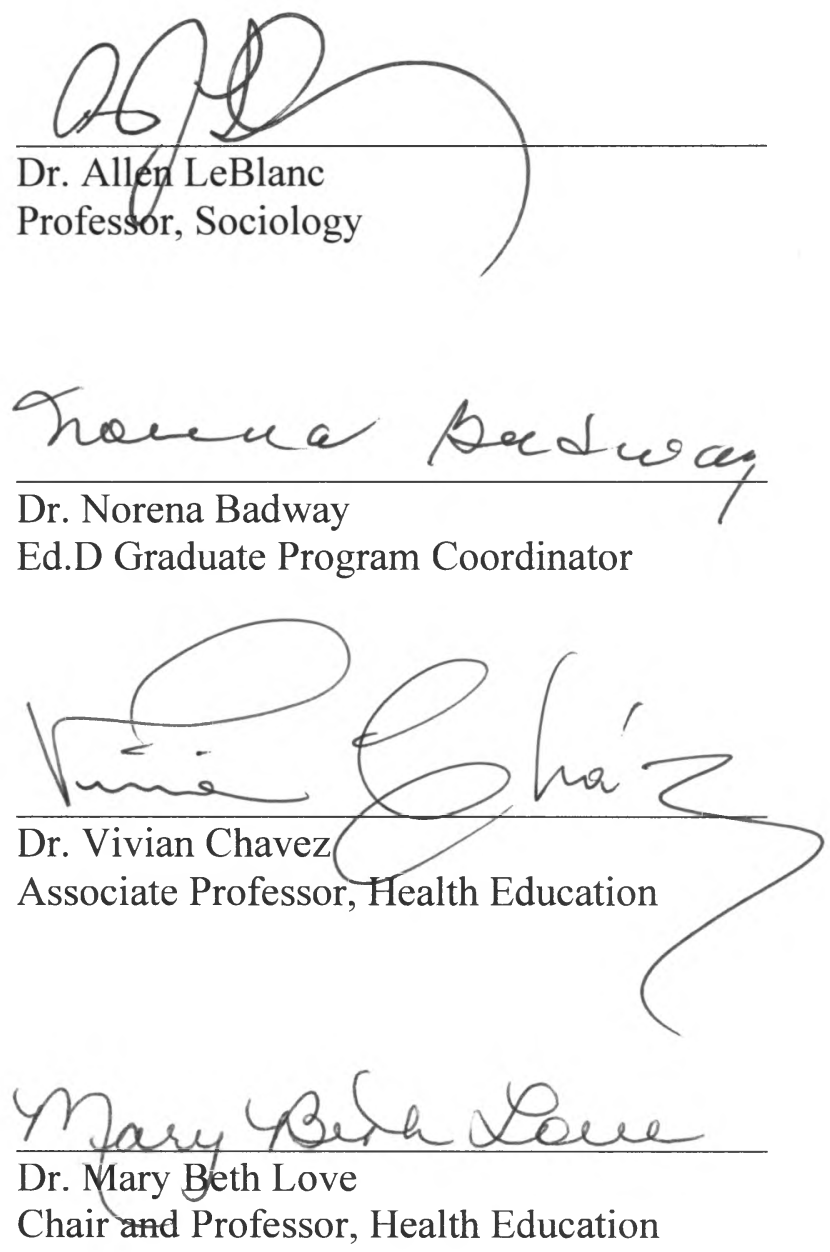


\title{
ENAGING IN THE BEAUTIFUL STRUGGLE: INFLUENCE OF FACULTY LEARNING COMMUNITIES ON TEACHING
}

\author{
Savita Kumari Malik \\ San Francisco State University \\ 2012
}

This study focuses on teaching experience and practice in post-secondary education - an important and understudied topic. I conducted an in-depth qualitative study of instructor experience in the Metro Academies' Faculty Learning Communities (FLCs), which currently operate at City College of San Francisco (CCSF) and San Francisco State University (SF State) in the Departments of Health Education and Child and Adolescent Development. As a Metro instructor and the facilitator of these FLCs, I worked with my colleagues and students, to apply Community-Based Participatory Research (CBPR) principles in the design and implementation of this research. Drawing from narratives of participating faculty gathered from in-depth interviews, I illustrate some of the most significant struggles that faculty face, including their persistent and pervasive fears of inadequacy and failure as teachers. This study also demonstrates the potentially promising role of FLCs in helping faculty embrace the inherent challenges of engaged and critical teaching, addressing their struggles as individual teachers, as well as their collective struggle as members of an FLC. The goal is to move from an isolated experience as a classroom instructor to a community-focused endeavor where critical pedagogy and reflection dominate discourse around teaching in post-secondary education.

I certify that the Abstract is a correct representation of the content of this dissertation.

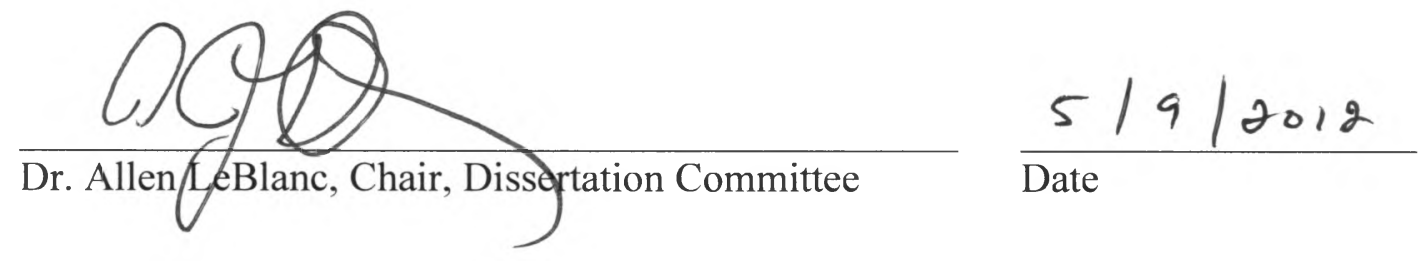




\section{ACKNOWLEDGEMENTS}

To my community, in all its shapes and forms, thank you, from the bottom of my heart. To my husband, Ezekiel Robles, who has been my rock and supported me unconditionally through these last three years. Words can't express my love and gratitude. To my mom, Rita Malik and best friend, Laurel Imhoff, who checked in on me often, and my dear family (Nanima, Geeta, Rishi, Jen, Viju, Jefe, Jefa, Maritza, Ronald, Crystal and Josh) Malik and Robles alike. I love you! To my Metro family, Tim Berthold, JoAnna DeVito-Larsen, Beth Freedman, Vicki Legion, Pat Murphy and especially to my amazing team in 301, Amie Fishman, Rama Kased, Maritza Pulido, for being my cheerleaders and supporters. You inspire me every day and I couldn't ask for a better team. To my incredible dissertation chair, Allen LeBlanc who found a way to be unbelievably supportive and still push me to make my writing and thinking better and better. You are amazing. To my fearless committee, Norena Badway, Vivian Chavez and Mary Beth Love, whose support and challenge made me, and this study, stronger. To my advisory group Amy Conley Wright, Cynthia Fong, Arai Buendia, Ann Marie Davidsen, Edgar Velazquez and Hermann Bormann. Your dedication and enthusiasm was infectious and kept me going. To my Metro faculty community, without whom this study would not have been created, thank you! Thank you for your honesty, authenticity and commitment to constant improvement. The work we do is so important. Keep on in the beautiful struggle! To my colleagues in my cohort who kept us all moving and focused. Especially to Laurie Scolari and Darrick Smith; you are my soul sister and brother. I couldn't have done this without you. Much love to all my community. 


\section{TABLE OF CONTENTS}

LIST OF TABLES ...................................................................................... vii

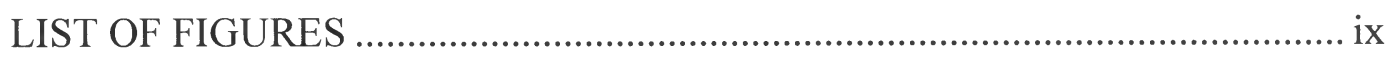

LIST OF APPENDICES ...............................................................................

Chapter One: Purpose of Study ........................................................................ 1

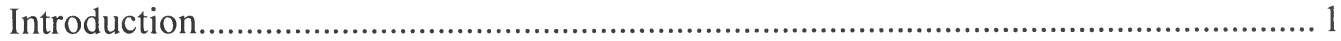

Lack of training and need for focus on instruction ................................................... 4

Purpose of the study ..................................................................................... 9

Metro program description ............................................................................... 10

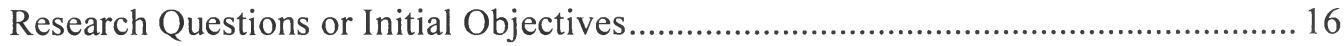

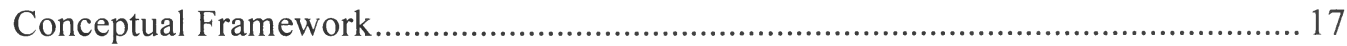

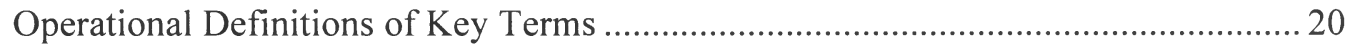

Statement of Delimitations and Scope of Study ………………………………....... 21

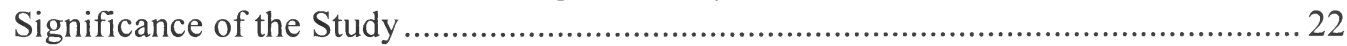

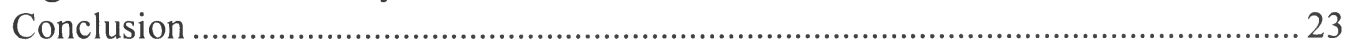

Chapter Two: Literature Review ................................................................ 24

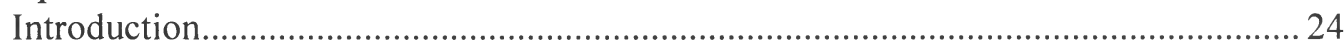

Scope and Structure of Review................................................................................. 24

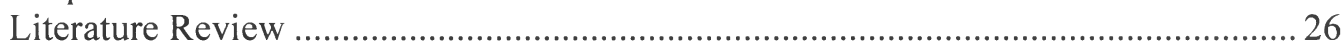

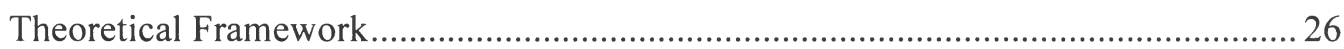

Purpose of a FLC: Building community ........................................................... 28

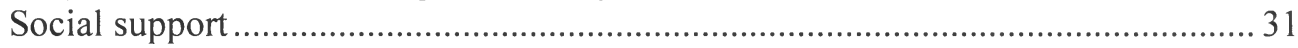

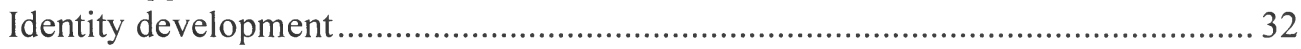

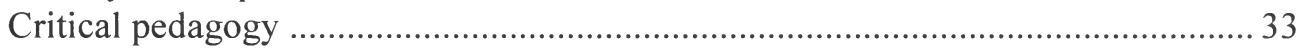

Culturally relevant pedagogy ………………………………………………….... 35



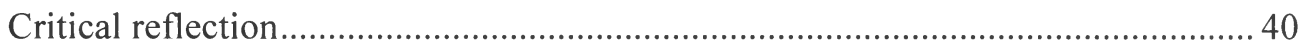

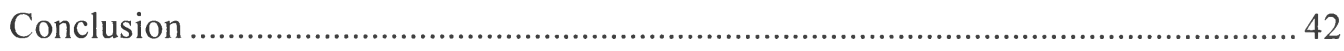

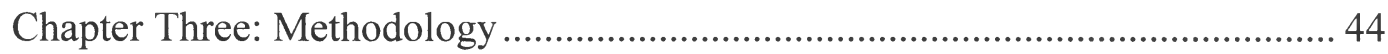

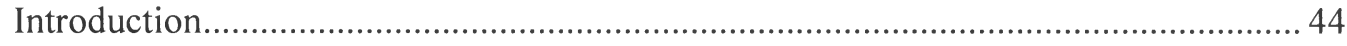



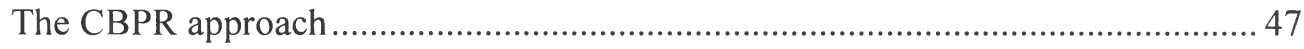

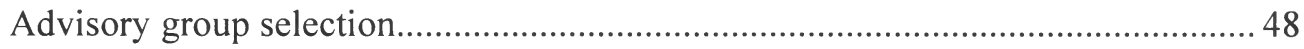

Role of advisory group in study ........................................................................ 50

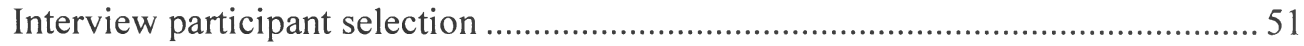

Demographic Data …………………………………………………………..... 52



Role of the Researcher and Context ........................................................................5 54

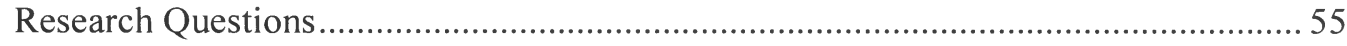

Ethics and Protection of Human Subjects .............................................................. 55 




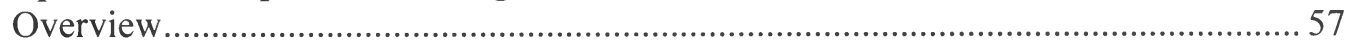

Motivations for Entering Teaching and the Metro FLC …………………………….... 58

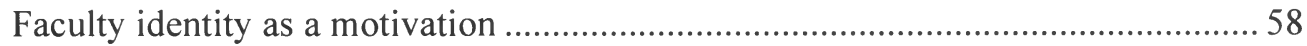

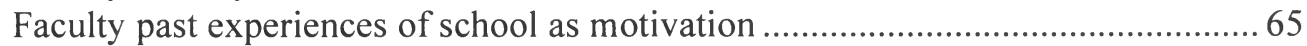



Fear of feeling unprepared .................................................................................. 68

Fear of inability to operationalize critical pedagogical principles ............................ 73

Positive Influence of the FLC: Addressing the Fear through Collective Struggle ........75

FLC builds skills and tools ................................................................................ 76

FLC allows deeper engagement with critical pedagogy ......................................... 79

FLC creates community and support structures for faculty ..................................... 82

Where the FLC Falls Short: Areas of Improvement....................................................8 87

Need a community for true self-reflection ............................................................ 90

How the FLC Influences Teaching Practice .................................................................. 92

Faculty acknowledge and make more visible the humanity in their students .......... 92

Power dynamics shift toward a more student-centered approach to teaching ......... 93

Faculty struggle to make content more relevant for their students .......................... 95

Faculty self-reflect and value having a community to reflect with ........................... 96

Continuing the Struggle: Moving Forward in Community ........................................... 98

Chapter Five: Discussion and Recommendations............................................... 100



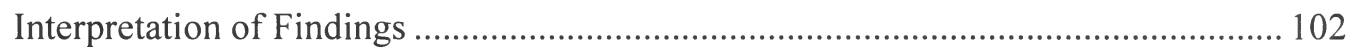

Motivations to teach in Metro ...................................................................................... 103

Fears and struggles of instructors in the FLC....................................................... 107



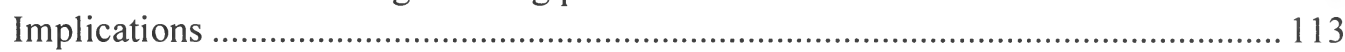

Reflection, Community, Action.................................................................................. 113

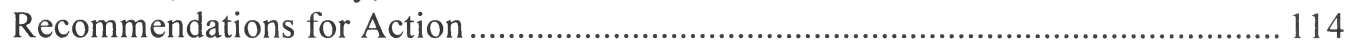

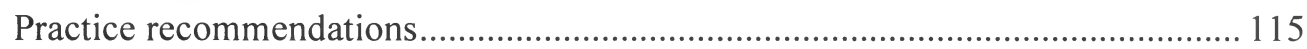

Policy recommendations ................................................................................ 116

Recommendations for further study ............................................................. 119

Reflections on the researcher ............................................................................ 121

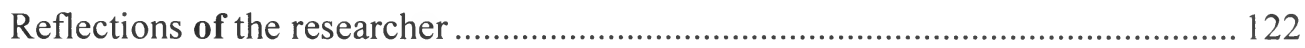

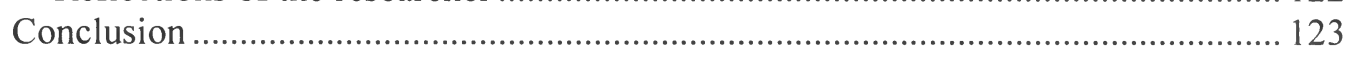




\section{LIST OF TABLES}

Table

Page

1. Advisory group members . 50 


\section{LIST OF FIGURES}

Figure

Page

1. Breakdown of Metro FLC................................................................................ 14

2. Conceptual framework from solo to collective struggle........................................ 18

3. Cycle of faculty transformation when engaged in a FLC .................................... 20 


\section{LIST OF APPENDICES}

Appendix

Page





Sample advisory group meeting agenda ............................................................. 139

Sample advisory group notes ........................................................................... 140 


\section{Chapter One: Purpose of Study}

The academy is not paradise. But learning is a place where paradise can be created. The classroom, with all its limitations, remains a location of possibility. In that field of possibility we have the opportunity to labor for freedom, to demand of ourselves and our comrades, an openness of mind and heart that allows us to face reality even as we collectively imagine ways to move beyond boundaries, to transgress. This is education as the practice of freedom (hooks, 1994 p. 207).

\section{Introduction}

Teaching to transgress; one of my favorite phrases by author bell hooks, describes the ultimate purpose of being an instructor and why I continue to teach as a faculty member in higher education. Teaching to push boundaries, to shift thinking and to educate for freedom of thought and spirit; it's why so many of us teach. Yet, teaching in higher education is often a very solo endeavor. There is a deep need for most of us, to struggle collectively, and to go to a place where we can talk honestly and openly about our fears. Where we can reflect, evaluate, go back to our classrooms, act, and repeat this process all over again. The impact of faculty on student success proves to be one of the most important factors in persistence and graduation in higher education, and this paper aims to examine the influence of faculty participation in learning communities on improved teaching practice (Bok, 2005; Cox, 2004; Kuh, 2008).

This chapter will explore the issues faculty members have in transforming their teaching practice. It will describe a faculty learning community (FLC) that instructors become part of when they elect to teach in Metro Academies; a program that provides linked courses, relevant curriculum and student support services for students in their first 
two years of school. This program aims to improve educational outcomes for lowincome, first-generation, underrepresented minority students at a community college or a four-year university through cohorted classes, targeted support and a faculty community committed to improving teaching and learning in higher education. This FLC gives instructors from two different institutions the opportunity to meet on a regular basis to share teaching successes and failures, learn from one another through structured facilitation, led by myself, and work generally to improve their teaching practice. I propose that participation in FLCs has an influence on higher education teaching practices and that faculty move from a more individualistic vision of their jobs as teachers, to a more collective vision where they work as part of a community of teachers. This dissertation describes the Metro program, discusses the problem of lack of instructional support for faculty and presents the research questions posed in the study. It also discusses the conceptual and theoretical frameworks that undergird the methodology, findings, as well as the scope of the study. Finally, it details the significance of the study to education equity. The following section details some of the major issues that faculty face as instructors in higher education that Metro attempted to address through participation in the FLC.

\section{Statement of the Problem}

The lack of focus on faculty development in post-secondary education has a markedly detrimental effect on the engagement of students and their educational achievement as over time (Elmore, 2004; Kuh, 2008). Post-secondary education has long 
been the principal means of social mobility, yet there is evidence that the quality of student learning in colleges and universities nationwide is declining (Kirsch, Braun, Yamamoto, \& Sum, 2007). Nationwide, only 66 percent of four-year college students complete a baccalaureate degree within six years, and of that percentage, employers continue to criticize higher education institutions, claiming many graduates are not ready for the workplace (Kirsch et al., 2007). For low-income, first-generation college students, the graduation rates from four-year institutions are even dire. According to a longitudinal, national study using data from student transcripts, first-generation students are more than twice as likely as non-first-generation students to leave college without earning a degree (Chen \& Carroll, 2005). There is much work to be done to improve educational outcomes for the population that Metro Academies serves, first-generation, low-income, underrepresented students.

George Kuh (2008) identifies a number of research-based high-impact educational practices that tend to benefit historically underserved students more than majority students. FLCs appear to be particularly helpful. His recent examination of FLCs found that when faculty meet and collaborate and have the opportunity to talk to one another, share lessons and discuss student successes and concerns, there is a noticeable increase in student persistence, greater student engagement, and higher student satisfaction (Kuh, 2008). The development and implementation of faculty learning communities in higher education are therefore, one way to shift the focus towards improving instruction, ultimately impacting student success (Cox, 2004). 
Chickering, Gamson and Poulsen (1987) delineate seven engagement indicators that directly influence student educational experiences. Five out of the seven addressed faculty behaviors, including encouraging active learning and cooperation among students as well as communicating high expectations. Without structured institutional time to have conversations about how to operationalize these principles, faculty are often left to themselves to figure out how to engage students. There are many barriers to improving instruction in higher education, including a lack of training and a need for a targeted institutional focus on faculty development, a need to integrate critical pedagogical principles into teaching practice, and an environment that promotes teacher isolation. Each of these areas will be explored in more detail in the following sections.

\section{Lack of training and need for focus on instruction}

Faculty members teaching in higher education institutions often lack the opportunity for skill development in active learning pedagogies, such as structured small group work that promotes cooperative learning and critical thinking with a focus on realworld issues. Post-secondary education is the only segment of education in the United States, in which instructors are never taught how to teach. Higher education institutions make an erroneous assumption; that knowledge of content confers expertise in how to deliver that content. In addition, there are few ongoing institutional processes for continuous quality improvement. Beyond teaching, instructors' heavy workloads and institutions' limited resources for institutional research mean that most faculty and administrators have few to no opportunities to review student outcomes data, or forge a 
common plan to improve outcomes (Bailey \& Alfonso, 2005). Brock (2010) notes, "Training and professional development are key [to bring effective programs to scale]. Ultimately many individuals — and not just a few champions — need to 'own' the ideas and apply the research lessons to their own context."

Bok (2005) says "most professors teach as they traditionally have, confident that the ways that have worked well enough in the past will continue to serve in the future (p. 312)." There is a definite lack of pressure to improve undergraduate education; a lack of shared responsibility for the academic growth of students and a reluctance to discuss issues of pedagogy as institutional research often takes precedent (Bok, 2005). This dearth of conversation around teaching and learning in higher education comes from a two-fold belief that (1) instructors are content experts and their methods come secondary and (2) the development of appropriate teaching methods is an individual endeavor (Bok, 2005; Grubb, 1999). Couple this belief system with the fact that most post-secondary instructors have no formal training in teaching, face increasing class sizes - likely due to budgetary constraints at most public institutions - and an increasing workload outside of their teaching responsibilities, and one can see why the quality of instruction continues to decline (Folbre, 2010; Grubb, 1999).

This increasing external pressure and lack of knowledge of innovative pedagogical methods directly affects student learning outcomes. Research demonstrates that teachers are not necessarily born, nor can just anyone teach (Darling-Hammond, 1999). While Darling-Hammond (1999) states with reference to K-12 teachers, that it is 
simply not enough to be a content expert; pedagogy training, long-term professional development and time for collaboration all play roles in the development of successful educators, the same can be said for faculty in higher education. Aspects of each of these elements will be discussed in more detail in the following sections.

\section{Lack of engaged teaching/Need to integrate critical pedagogy}

Elmore (2004) describes classrooms in which the instructor is the main source of information and activities have a marked teacher focus. He discusses that within these classrooms, instructors make significant shifts to the dominant ideology that the instructor pours knowledge into a student and that they are passive recipients of that knowledge. He defines the instructional core of teaching and learning as how teachers understand the nature of knowledge, the student's role in addition to the structural arrangements of schools including classroom setup, student grouping norms, relationships among instructors in addition to processes for assessing student learning and ways to communicate with important stakeholders, including students, teachers and parents. He argues that in order to increase student learning, institutions must increase the frequency of focus on the instructional core by shifting the center from teacher to student. This specifically includes increasing the time faculty spends on improving their teaching practice, as well as the quality of their lessons (Elmore, 2004). In a fifteen year study of nearly one hundred college teachers, Bain (2004) defines excellent teaching as success in helping students learn in ways that make a deep influence on how they think, act and feel. He claims that the best college teachers know their content, have high expectations of 
their students, and prepare lessons completely. They approach teaching as a serious intellectual endeavor; as intellectually demanding as their research and scholarship (Bain, 2004). Duncan-Andrade (2007) echoes Elmore (2004) and Bain (2004), arguing that duty towards teaching and extensive preparation make excellent educators. The teachers he profiled in his study shared the feeling that being a teacher is "who I am, not what I do" (p.628).

In addition to preparation and duty, Duncan-Andrade (2007) claims that educators must have a critically conscious purpose in understanding the history of the communities they work with. Bartolome (2004) links this purpose with critical pedagogy in her study of four exemplary educators. Critical pedagogy comes from a school of thought rooted in critical theory that places teaching within a context; it aims to expose the myth that educators are objective and looks to develop the critical capacities to reflect, critique and act to transform the conditions in which they currently live (Darder, 1991). Bartolome (2004) argues that the integration of critical pedagogy into teacher education has a profound impact on student engagement and success. She identifies educators who are aware of power dynamics and who reject deficit views of their students. The teachers in this study articulated the fact that other factors, such as racism and poverty play a larger role in their students' lives than merit does. They have the opportunity to explore and expose students to "alternative explanations for the academic underachievement of minorities, the myth of meritocracy," and to critically examine their own biases as educators when working with students (Bartolome, 2004, p.116). Through this process of 
self-reflection and a critical consciousness about the reality of the world, educators have the ability to change systematic subjugation of particular student communities and thereby engage more deeply in their teaching practice (Bartolome, 2004; DuncanAndrade, 2007).

\section{Lack of collaboration/Teaching in isolation}

In his qualitative study of community college instructors, Grubb (1999) found that faculty isolation plays a key role in preventing effective instruction. He interviewed and observed 257 instructors to develop a definition of good teaching, as measured by teacher questions, classroom interactions and student reported engagement, as measured through classroom observations. His findings showed that most instructors get no support in rethinking their practices and faculty stated that they wanted professional development that was integrated and sustained into their work. They also had a desire for activities that fostered collegiality between colleagues (Grubb, 1999). One English faculty member noted that he joined a learning community of faculty because he felt isolated and that his teaching had gone stale. He valued the interactions with faculty and felt that there was a lot of informal sharing of teaching techniques, even when that was not the central focus of the FLC meeting (Grubb, 1999). Most importantly, this study suggested that the most memorable teaching came from instructors who had created communities of colleagues where they were able to share their practices and the worst instructors had managed to stay in virtual isolation (Grubb, 1999). This study on community college instruction further proves the need for FLCs at all levels of higher education. 


\section{Purpose of the study}

This study aims to add to the body of literature that discusses the influence of FLCs on teaching practice. Pascarella and Terenzini's (1991) How College Affects Students review of nearly 2,600 studies on the impact of college was conducted over the thirty-year span from the 1970s through the 1990s. The book emphasized the importance of the nature and frequency of student contact with peers and faculty members as well as interdisciplinary or integrated core curricula that make explicit connections across courses and among ideas. They also discuss pedagogies that encourage active student engagement in learning and application of what is being learned in real and meaningful settings, as vital to retaining students and moving them towards timely graduation. FLCs can give instructors the tools they need to create classroom spaces that foster integration of content and sharing of practices that improve student engagement, and ultimately, student success.

As facilitator of the Metro community, I wanted to find out how bringing faculty together could elevate and honor our work as educators. I wanted to explore ways that the FLC could be strengthened and as well as the ways in which the FLC worked to transform teaching practice. The Metro FLC serves as a case study in this context, by which we can learn about the power as well of the challenges that emerge when faculty come together to examine their teaching. This study adds to the literature on the influence of FLCs on faculty. It also integrates theories of critical pedagogy and social support key mechanisms in helping instructors shift their teaching practice. What follows 
is a detailed description of the Metro FLC, highlighting its differences and similarities with other FLCs.

\section{Metro program description}

In 2007, the health education departments at City College of San Francisco (CCSF) and San Francisco State University (SF State) formed a partnership to help students persist through the first two years of college and improve their writing skills before they entered the major. This program, Metro Academies, represents a redesign of the freshman and sophomore years, when students at public institutions are most likely to drop out (Bowen, Chingos, \& McPherson, 2009; Moore \& Shulock, 2006; Pascarella \& Terenzini, 1991). Metro is a multi-semester cohort-style learning community program, in which first-generation, low-income, underrepresented students study together in two required linked classes over three to four semesters, engaging students early in some of the big questions in a field of interest, such as health or education. Students are encouraged to support each other academically and socially, and to form strong relationships with faculty. If a student stops out, the program stays in close communication and strongly encourages him or her to step back in. The model provides simultaneous, nearly identical programs for the first two years at both CCSF and SF State. With faculty from both segments working together on curriculum and assessment tools, this design fosters a very close alignment between the community college and university. 
In each semester, the Metro course pathway contains a linked pair of courses that share themes, combining a required general education (GE) course in one of four foundation subjects—critical thinking (Semester 1), oral communication (Semester 2), writing (Semester 3) and quantitative thinking (Semester 4), —with a second GE course. Metro's long-term mission is to increase equity in college completion through engaging, supportive, rigorous, and socially relevant education. Within this mission, are more proximal goals of helping students navigate college life, build general education skills (such as writing, etc.), and develop meaningful relationships with fellow students and faculty members.

\section{Metro FLC: Faculty collaboration}

One of the most unique aspects of the program is the interaction that faculty have with colleagues in six different departments and two different institutions. The Metro program consists of an interdisciplinary faculty community with members in composition, ethnic studies, math, health education, child development and oral communication across both campuses. The development of the community represents an innovative approach to professional development. Being a part of the Metro faculty community gives instructors the opportunity to meet once a month to develop engaging pedagogy, share best practices, and maximize alignment between the community college and state university. Metro leadership made a clear case for the need for focus on teaching and learning through a series of conversations where faculty discussed the qualitative factors that made teaching difficult. As a community, the members then 
decided on focus areas that they could control within the institution to improve student learning. No blame was assigned to instructors; on the contrary, the collective decision to work on aspects of teaching practice came organically and holistically from those actually in the classroom (Eckel, Hill, Green, \& Mallon, 1999).

Metro FLC: The learning community

Metro hosts a structured FLC that provides 45 hours of professional development over a minimum of two years (See Figure 1). Faculty members learn how to use evidence-based educational practices to provide interactive, engaging instruction. Instructors build a strong culture of collaboration focused on student success and regularly review student success data to inform decision making about how to shift classroom instruction to improve grades, retention and persistence between semesters (Leana, 2006). Faculty participants in the FLC meet once a month to talk about teaching practices, share experiences and reflect on their own struggles in the classroom. They discuss issues of education equity through the larger context in which our students attend college. Faculty also meets separately by campus to talk more specifically about experiences unique to teaching at each institution. At these site-based meetings, instructors review the progress of every student, and plan interventions for individual students and for program improvement when they identify a pattern of needs. Instructors of linked courses also have time to synchronize the class content, identifying common themes and readings that link two courses. For example, a health instructor asks her students to develop a policy brief on a health issue her students care about. Students are 
simultaneously taking a statistics course, so the math instructor uses policy examples to teach the statistics concepts and the health instructor requires statistical knowledge be demonstrated in the final policy brief paper. Faculty members are strongly encouraged to observe each other's classes, and they generally do. There is also frequent informal contact among teachers for trouble-shooting and resource sharing. For example, faculty interact with one another on campus during their collective time out of the classroom (both in person and through email) where they have conversations about what happened in a previous class and brainstorm together on how to improve subsequent lessons. Instructors may borrow items from a curriculum library of books, DVDs and curriculum guides, that is built collectively thorough the Metro program and lives in the coordinators' offices at both institutions. The goals for faculty participants in the Metro FLC are to improve teaching pedagogy, integrate courses with relevant curriculum, and find ways to support students and fellow faculty members through consistent face-to-face meeting time. 


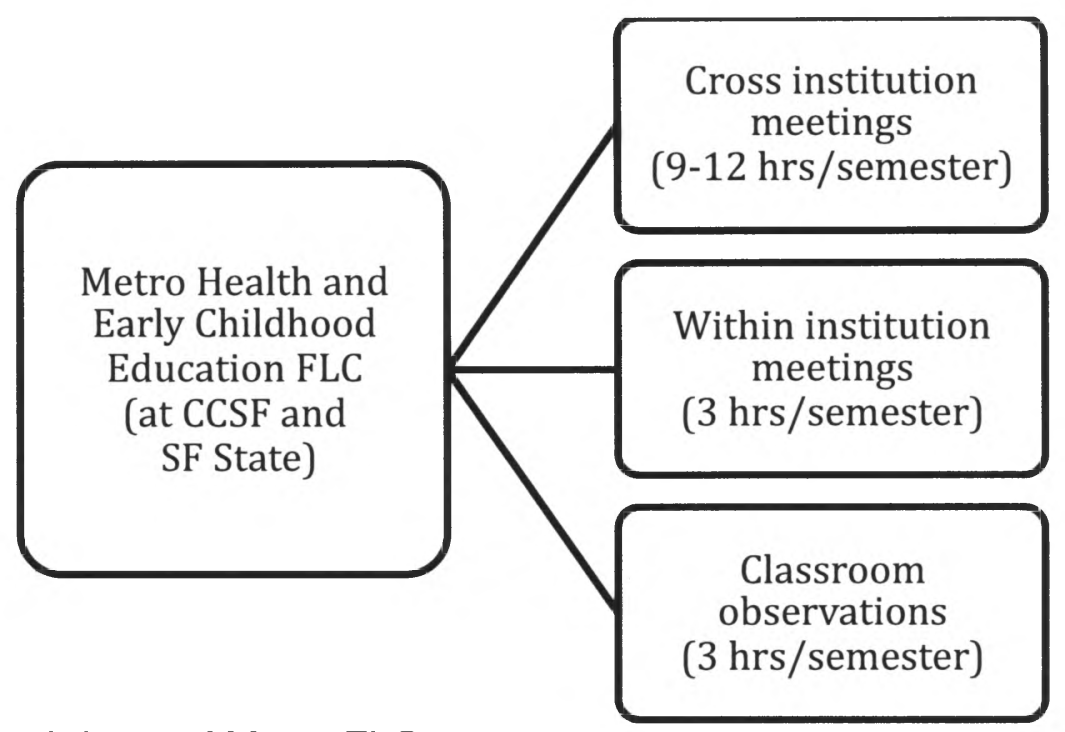

Figure 1. Breakdown of Metro FLC

Faculty members meet once a month or a minimum of 12 hours per semester, to discuss best practices in teaching across the two campuses. They also engage in more targeted development (with time for training on teaching writing, and curriculum infusion, for example) during the summer months for two to three days of intensive training for a total of 16-24 hours. Once the student cohort begins, faculty members work together to help each other see students holistically and strive to make personal connections, help them develop an education plan, promote counseling services, and create an early alert system for students that may be slipping academically. Instructors also strive to consistently assess their impact, focus on building writing, critical thinking, oral communication, and quantitative reasoning skills in themselves and their students and hold high expectations of each individual involved in the program. Moreover, they engage in a critical analysis of complex social problems, create authentic assignments, 
and teach meaningful content. Furthermore, participating faculty are asked to visit each other's classrooms to observe new strategies and offer their feedback to one another.

As incentive for participation, faculty members were paid a $\$ 500$ per semester stipend for attendance at the monthly meetings. The vision is that FLC participants take what they are learning and apply it to other courses they are teaching in their home departments, spreading professional development throughout their institutions. This study focuses on this diverse group of faculty who teach first- and second-year undergraduates at both partner institutions, and examines the influence of the FLC on teaching practice.

\section{Metro FLC: Mission and goals}

Within the last year, the Metro FLC worked to define a mission statement; one that reflects the values of the program and asks faculty to link our collective consciousness around teaching to the larger goal of student empowerment. Our mission is:

We wish to empower learners to assert their own narrative and to value the communities they come from. We take an asset-based approach to students and commit to processes of reflection and improvement in our classrooms and overall teaching practice. We look to give learners a clear understanding of structural factors that influence communities, the knowledge and skills to work against the systems that perpetuate inequity, and ownership over their own education.

This mission is grounded in visions of social justice using critical pedagogy as a lens to analyze our teaching practice and reflect on why we make particular decisions as instructors. We use critical pedagogy to "define and critique power relations, in ways that promote the transformation of existing educational inequalities" (Darder, Baltodano, \& 
Torres, 2008). Our belief in social justice asks our faculty to critically analyze structures and systems of oppression, liberation, resistance and resilience, have a commitment to academic excellence and rigor for all students and work to create relevant and authentic learning experiences for students that are multicultural, anti-racist, and pro-justice. These features of the Metro FLC are unique in that research rarely shows the integration of such principles into faculty development practices in higher education. In addition to a critical pedagogical lens, faculty development in Metro also promotes methods of engaged teaching. We work hard to get one another to step out from behind the proverbial podium, to develop and share active learning techniques as part of building instructor repertoire and confidence and to take risks and try new ways of imparting information. One of our most important goals is to get students to think critically, and this requires us as instructors to add variety to traditional teaching methods. Faculty need faculty development that addresses both structural factors, including training, and time and space to be in community, along with more process-oriented factors, including engaged teaching techniques and support developing critical consciousness, to create an experience that has the potential to be transformative.

\section{Research Questions or Initial Objectives}

The primary question that emerged from thinking about FLCs was how do faculty learning communities affect higher education teaching practices? Some sub questions include: What motivates people to teach in a faculty learning community? What are the struggles that faculty members face in striving to be better instructors? Finally, how does 
participation in a faculty learning community influence teaching practice? In what ways do they have an influence? Faculty experiences of teaching before and during participation in the community will be seen as central to the data collection in this study. Based on observations and a review of the literature, I propose that participation in faculty learning communities does have an influence on higher education teaching practices.

\section{Conceptual Framework}

Teaching in higher education is all too often a solitary struggle. Faculty are typically underprepared, working in institutions where issues of teaching practice are not the predominant focus (Bok, 2005; Darling-Hammond, 2010; Hutchings, Huber, \& Ciccone, 2011). As a result, many faculty members work in solitude, without a space to share fears, concerns and successes in their classrooms. Through engagement in a FLC this solo struggle can become a collective struggle. FLCs can help instructors work together to face fears, support one another and challenge each other to reflect deeply on their teaching practice. In short, the FLC has the potential to help groups of participating faculty members work together become more effective educators. Figure 2 details the conceptual framework for this study in greater detail. 


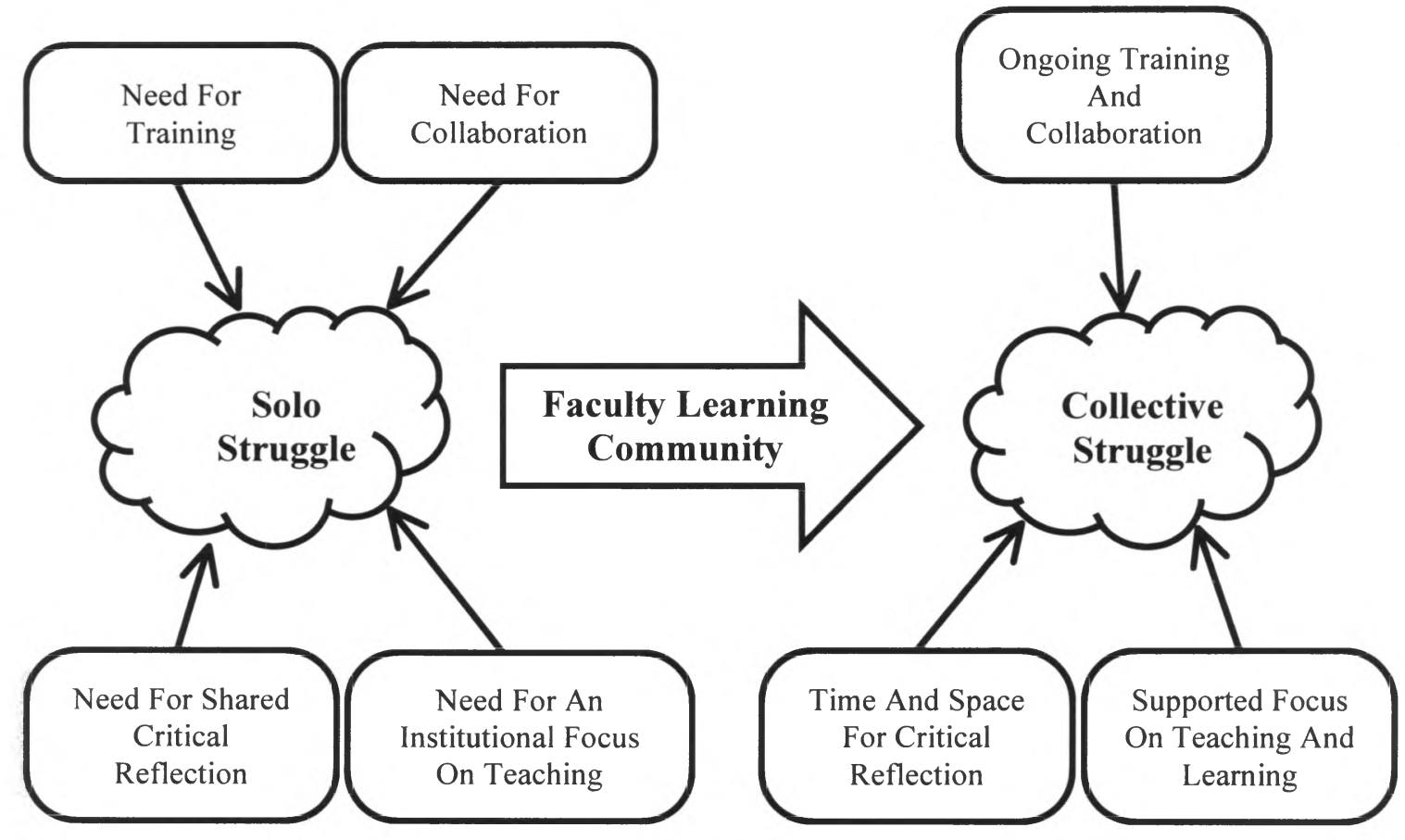

Figure 2. Conceptual framework of solo to collective struggle

The Metro FLC aims to provide space for faculty to come together, gives opportunities to build skills and techniques through training and has a supported focus on teaching and learning with a student-centered approach to instruction. The FLC devotes time for instructors to reflect on teaching practice in conjunction with a move towards analyzing our practice with a critical pedagogy lens. These elements shift faculty examination of their teaching practice from a solitary struggle to a collective one. There is little doubt that accomplished teaching requires knowledge of content, pedagogy, identity, context and relevance for students. There is a fundamental assumption that underlies this definition of accomplished teaching; that teachers do not have to be born 
phenomenal instructors - they can learn to teach. While these assumptions are often spoken about when talking about teachers in K-12, my belief is that we need to shift structures in higher education to allow similar communities of practice for instructors in college and university settings, thereby giving space for teachers to learn to teach.

Community spaces for faculty to come together must also include ways for faculty to undergo the same process as their students in the classroom. One of the hallmarks of critical pedagogy is that students need to go through a process of unlearning dominant ways of thinking that reinforce power dynamics that can impede the learning process (Darder et al., 2008; Freire, 2000). Faculty must go through the same process of unlearning, learning, relearning, reflection and evaluation, in order for them to be teachers that work for social justice and social change. Some of the theoretical constructs that fit into this framework include essentialism (unlearning), social justice education (learning), critical pedagogy (relearning), critical reflection (reflection) and using a community of practice and social support to guide transformation (evaluation). Figure 3 shows this cycle and places it in the context of the faculty learning community and is based on principles of critical pedagogy (Darder et al., 2008; Shor, 1992). 




Figure 3. Cycle of faculty transformation when engaged in in a FLC Operational Definitions of Key Terms

Because there are varying interpretations of what constitutes a FLC, below are some definitions of key terms outlined above in the research questions. The Metro FLC differs from many other types of learning communities as they meet across two institutions on a regular basis. In this study, a FLC refers to a group of faculty who get together regularly in a structured format to exchange ideas about teaching, build community, support one another, reflect on teaching practice, further develop critical 
pedagogy and curriculum and participate in professional development workshops.

References to teaching practice include classroom management, curriculum development, lesson design, active learning strategies, the incorporation of relevant issues and reflection to guide instruction growth and change.

A key element of the Metro FLC is the use of critical pedagogy to guide professional development, as well as reflective practices that engage faculty in thinking about their own teaching. To reiterate, critical pedagogy looks at,

Habits of thought, reading, writing, and speaking which go beneath surface meaning, first impressions, dominant myths, official pronouncements, traditional clichés, received wisdom, and mere opinions, to understand the deep meaning, root causes, social context, ideology, and personal consequences of any action, event, object, process, organization, experience, text, subject matter, policy, mass media, or discourse. (Shor, 1992, p.129)

Statement of Delimitations and Scope of Study

This study looks at faculty perspectives on their teaching practice and allows space for them to explore their personal narratives around teaching in higher education. This builds on existing literature that validates the practitioner experience and engages faculty in discussions of their own teaching (Duncan-Andrade, 2007). The faculty participants engage in a unique version of a FLC and so the findings are specific to this format. On the other hand, some of the lessons that emerge as a result of the interviews can be generalized to other similar institutions, as the need for faculty community comes through in a strong way. This study does not examine student's perceptions of faculty transformation. 


\section{Significance of the Study}

This study uses a community-based participatory approach to explore how FLC members perceive their own teaching practice after participation in the Metro FLC. I hope to add to the body of literature concerning FLCs, particularly by adopting a criticalpedagogy lens to faculty development in higher education. Professional development is often discussed as a series of skill-building workshops that do not have a plan for where faculty start, and where they are going. Through conversations with Metro FLC participants, I hope to look deeply at both strengths of the existing FLC and ways to improve it. The more we can improve our teaching practice, the better engaged and more successful our students (especially underrepresented, first-generation, low-income) will be in their college years (Elmore, 2004; Pascarella \& Terenzini, 1991).

I also hope to that a community-based participatory research (CBPR) approach to this project will inform the development of new research methods for studies of teaching effectiveness. The CBPR approach lends itself to a critical examination of knowledge and practices that ultimately influence student outcomes. Conducting research studies with the communities involved in every aspect of the study, can lead to more authentic and shared experiences, reminiscent of the community one is trying to profile (Israel, Eng, Schulz, Parker, \& Satcher, 2005; Minkler, Wallerstein, \& Hall, 2002). It would be difficult to approach a study of this nature without taking into account the identities and needs of my fellow faculty members and without students. 


\section{Conclusion}

Higher education institutions produce content experts who teach at community colleges and four-year universities. However, there are many barriers that keep faculty isolated from their peers, struggling alone to improve their teaching practice. Through participation in a FLC, faculty members have the opportunity to reduce isolation and gain skills through a cycle of unlearning through evaluation that repeats as faculty elevate their teaching over time. As hooks (2004) mentions in the quote at the beginning of the chapter, the classroom is a place that holds so much potential and possibility, I would argue, for both the student and the instructor. Engagement in an FLC allows time and space for faculty members to explore the depths of what they do in their classroom, and how students react to their decisions and behaviors. The following chapters detail the study conducted on 15 Metro FLC participants. Chapter 2 gives a literature review, beginning with a brief history of FLCs and continues on to discuss the theoretical constructs depicted in Figure 3. Chapter 3 delineates the methods of the study, including the CBPR approach described earlier in this section. Chapter 4 details the findings of the study based on the conceptual frame in Figure 2. Chapter 5 concludes with a discussion and recommendations at both a practice and policy level. 
Chapter Two: Literature Review

\section{Introduction}

Faculty members committed to elevating teaching practice engage in an ongoing exploration of their identities as teachers, the assumptions and biases they bring into the classroom and why they make particular decisions on their teaching. This process of selfactualization often happens as a result of instructors seeking spaces outside the college or university to talk to colleagues about their teaching practice. This study examines the influence of a FLC that spans two institutions on transforming teaching practice for a group of Metro faculty. This chapter introduces a conceptual framework for better understanding how instructors can join together in a collective struggle through a structured exploration of self and one another.

\section{Scope and Structure of Review}

This literature review pulls from a number of different traditions. This section focuses on explanations of communities of practice in psychology and health to detail behavior change through social support. It also uses theories of schooling and educational practice to explore the importance of critical pedagogy. Databases such as EBSCO host and Academic Search Premiere were used in addition to Google Scholar. Terms such as professional learning communities, communities of practice and faculty learning communities were added to words such as higher education, community college, university, critical pedagogy, reflection, influence and impact. I also draw from books that examine different aspects of the teaching process and the influence of community on 
shifting teaching. In addition, the journal New Directions for Teaching and Learning released a special issue devoted to FLCs in 2004 (Cox) and there are a few publications released within the last two years that gave a more updated look at communities and partnerships between institutions (Hutchings et al., 2011; Yonezawa, Jones \& Singer, 2011).

A review of the literature revealed particular gaps in the research on FLCs in higher education. Relatively, there is a great deal more literature on communities of practice in the K-12 system, but the discussion about good teaching in higher education is a more recent phenomenon. There is also little written about cross-institutional collaborations. One study discusses a FLC partnership between a high school and university. There were positive outcomes from this collaboration, however, the focus was literacy, with both groups working to develop particular projects that integrated university and high school settings (Jetton, Cancienne, \& Greever, 2008). Faculty did learn from one another; however the FLC had a timed end, which is different from the Metro FLC, which is ongoing. Very little is written about a FLC that spans two sectors of higher education: the community college and the university.

Also, there is little published on the importance of integrating a critical pedagogy lens through culturally relevant teaching into faculty development in higher education. Some have written about training K-12 teachers to adopt critical pedagogical principles in lesson design, classroom management, and classroom setup as an important part of improving instruction (Bartolome, 2004; Bigelow, 2004; Darling-Hammond \& Sykes, 
1999). Beyond general discussions of diversity within faculty learning communities (Petrone, 2004), little is known about how the curriculum and structure of a FLC in higher education can lead to faculty transformation through exploration of critical pedagogy within teaching practice. This will add to the literature on professional development, faculty learning communities guided by critical pedagogy and a deep internal look at one's teaching through the support of colleagues both within and across institutions.

\section{Literature Review}

In this literature review, it is important to note that there will be three different terms used; critical pedagogy, social justice education and culturally relevant teaching. These three concepts intersect in a myriad of ways, with critical pedagogy being the overarching idea that encompasses social justice education and culturally relevant teaching. These concepts will be clarified in the following sections.

\section{Theoretical Framework}

The theoretical framework for this study is based on several different components. At the base, is a community of practice, where faculty members support one another and work together to elevate teaching practice. On the outside, there is reflective cycle as described through the lens of critical pedagogy, which uses several steps to explore how people transform, of unlearning, learning, relearning, reflection and evaluation (Darder, 1991; Darder et al., 2008; Shor \& Freire, 1986). The FLC that encourages collective transformation uses a belief in critical pedagogy and social justice to implement faculty 
development programs. At the heart of this is movement toward developing culturally relevant curriculum and pedagogical ideals for their students, sharing effective teaching methods and content and self-reflection where faculty are working together to improve their teaching.

In addition to a focus on the instructional core, research shows that all students benefit from a model of culturally relevant teaching, which comes from an integration of personal, moral, social, political, cultural and academic knowledge and skills taught in tandem (Gay, 2000). Students are taught positive ethnic identity development while learning about the contributions of cultures outside their own. The link between culture and instruction comes from research and evidence that cultural practices shape thinking and cognitive structures and that context both inside and outside the school is vital to engagement and retention of course material (Ladson-Billings, 2009). Thus, culturally responsive education uses respect for students' identities and backgrounds as important content to create meaningful for learning environments (Nieto, 2003). This theoretical framework has implications for improving teaching and learning of in higher education, both at the community college and university level, as there is little in the literature that talks about institutional structures for incorporating critical pedagogy into professional development.

An additional element that proves critical for transformational development of faculty is the integration of deep critical reflection. Reflective practice can allow instructors to "examine their beliefs, frames of reference or assumptions that implicitly 
guide or influence their practice" (Bernacchio, Ross, Washburn, Whitney, \& Wood, 2007, p. 1548). In other words, it gives faculty time and space to make sense of the purpose behind particular classroom behaviors.

In summary, the three theoretical constructs that undergird this study are the focus on community as a means of social support, the important integration of critical pedagogy in faculty development and the need for deep self-reflection with together, work to transform teaching practice. The following sections of this chapter explore the purpose of a faculty learning community and explore the theoretical constructs in greater detail.

\section{Purpose of a FLC: Building community}

Over the past thirty years, faculty learning communities have become widely discussed as forums for professional development. Participation in a faculty learning community creates a loop of planning, action and reflection that can increase instructor effectiveness. It has the potential to create connections for isolated teachers, foster multidisciplinary curricula, and establish a forum for discussing pedagogical issues (Cox, 2004).

FLCs have been defined as collegial groups of faculty who are committed to the improvement of their teaching through discourse and discussion through goal setting (Cross \& Steadman, 1996; Levine \& Shapiro, 1999). Research conducted at Miami University shows that there are two major categories of FLCs. Some are cohort-based, with the curriculum depending on the nature of the group of faculty and their needs, and others are topic-based, with the FLC designing curriculum based around a specific need, 
issue or opportunity (Cox, 2004). The goals of most FLCs are similar: build community, increase interest in teaching and learning, increase collaboration across disciplines and create awareness of the complexity of teaching as a practice. Faculty members need a "safe, non-competitive, collaborative and encouraging space to improve their teaching practices" (O'Banion, 1997). The development of FLCs can provide a space for ongoing learning and improvement of classroom practice (Cox, 2004; Darling-Hammond \& Sykes, 1999). One model of a faculty community in included shared values and vision, collective learning with a direct classroom application, shared practice and supportive conditions for the maintenance of the community. Little (1993) and McLaughlin \& Talbert (2003) add reflective dialogue, collective responsibility for practice, professional growth, and mutual support as key themes for developing an effective faculty community.

FLCs derived from the notion of student learning communities. Kuh (2008) and Meikeljohn (2000) describe student learning communities as places for students to come together where learning was based on their needs and connected curriculum across disciplines. This model has been modified to interpret faculty members as the learners, but embodies many of the original principles for why student learning communities can be effective. Learning communities are believed to improve student engagement and outcomes, in part because they view knowledge as changing and growing, not static (O’Banion, 1997). In a study of new faculty, findings echoed studies completed a decade earlier: new faculty worry about a lack of community and want to work in places where 
collaboration is respected and encouraged (Austin, 2000; Sorcinelli, 1992). In a study of more established faculty in a Canadian university, researchers found that faculty who were satisfied after lengthy careers in the academy, felt that they were part of support networks that helped reduce isolation and were part of environments where colleagues stimulate each other's interests as members of a team working together to address issues (Karpiak, 1997). Thus, it appears that FLCs hold potential for faculty in different stages of their careers, offering support and opportunities to collaborate they may not get elsewhere.

Studies show that the strength of professional relationships developed between instructors, influences the degree to which their practice transforms. In order for instructors to shift instruction in the classroom, there need to be more opportunities to develop faculty community. The link between learning and practice derives from the communities-of-practice perspective, which postulates that learning does not occur within the individual mind; rather it happens as a result of shared practices, social resources and common views (Lave \& Wenger, 1991). Individuals working together cultivate stronger ties within a community than in the larger society, which can seem impersonal and alienating. Putnam argues that we are less grounded by place-based communities and are becoming more and more individualistic in our daily encounters (Putnam, 1995). Faculty communities, when run effectively, can ease the burden on instructors and make teaching more meaningful. 


\section{Social support}

Social support theory comes from the premise that having people you trust and who care for you in your life, improves physical, emotional and mental health (Glanz, Rimer, \& Lewis, 2002). Just as for students, deep learning often happens through social interaction, where people learn together (Lieberman \& Pointer Mace, 2008). Leaders in teaching and learning promote continuous blocks of time where faculty are in community as an opportunity to build social networks and improve instruction (Lieberman \& Pointer Mace, 2008). While this is often limited to teacher training programs for those entering $\mathrm{K}-12$, I propose that faculty in higher education can benefit in the same ways.

A recent study of teacher retention and resilience found that the social support developed within a learning community allowed faculty to explore their practice more and, ultimately, to more effectively navigate "top-down mandates", such as changes in how students are placed into English classes, for example and manage classroom-level struggles including attendance, participation and completion of work in a timely manner (Yonezawa et al., 2011). Glasser (1986) argues that one key to motivation is to remove students from their isolationist educational experiences and help them become a part of a peer group with similar goals to encourage them to work together to achieve. His theory suggests that learning groups satisfy the four basic psychological needs for students: belonging, power, freedom, and fun. They also help individuals realize the connection between power and learning, giving them the autonomy to become independent thinkers 
and learners which leads them to success in various avenues of life (Glasser, 1986). This argument should hold true for FLCs as well.

\section{Identity development}

Communities of professionals come together in various venues to improve collaboration. Members of similar professions share a sense of common identity and language; "they share the same role definitions in relation to members and non-members alike; they share a common language; and they control the reproduction of the group through selection procedures and socialization processes" (Grossman, Wineburg, \& Woolworth, 2001, p. 9). William Goode (1957) highlights the difficulty in developing professional communities within the school structure. Within systems of higher education, faculty often have little power in who gets hired in their departments, the amount of time that is dedicated to teaching and learning, and must exist within norms of retention, tenure and promotion. Often, these structures stand in the way of creating sustainable professional learning communities.

Given the limitations of the structural elements in higher education, the need for localized, substantive professional communities becomes even more vital in sustaining educators' enthusiasm for excellent teaching. Situated learning in communities of practice is an important element in any faculty group. Lave and Wegner (1991) discuss how the connection between learning and practice develops in social spaces and when shared across experience levels, beginning instructors mirror the practices of more seasoned educators. Gallucci (2008) in her study of Highline School District's 
instructional reform methods, looks at individual transformation of practice and states that idea development can be shared, creating a fluid culture of professional learning. In this way, professional communities stem from Vygotsky's (1978) theories that learning is social in nature and that teachers require support from more experienced peers to increase their knowledge acquisition and content curriculum until they can sustain their learning independently (Darder, 1991). Development of communities of practice, sharing and open dialogue seems to add value to instruction and faculty experience in the classroom.

In the following section, I examine critical pedagogy and reflective practice as key elements to elevating teaching practice. This forms the basis of further discussion of a framework that looks through a social justice lens at faculty development. This includes a focus on developing culturally relevant teaching and unlearning some of the biases and assumptions that we make as instructors. I pay particular attention to essentialism, where populations of people are reduced down to broad generalizations of the entire group, which can be uniquely destructive as we look to diversify the faculty at our institutions.

\section{Critical pedagogy}

Critical pedagogy is the foundation for this theoretical analysis. This framework asks fundamental questions of power differentiation, consciousness of education as freedom leads into an overall social justice standpoint on education and teaching as a whole. It incorporates Gramsci's (1971) view that a deep understanding of the dominant worldview and societal constructs is necessary to resist the structural forces that cause oppression. He argues that there is a real connection between power, history, politics, 
culture and pedagogy (Gramsci, 1971).

Critical pedagogy stems from a Marxist perspective in which power differentiation between the elite and non-elite members of a society is acknowledged and resisted. Dewey (1910) argues that schooling in the United States should be a vehicle in which students develop a foundation for participation in a democracy. His claim is that educators need to provide environments in which resistance to social control is both welcome and encouraged (Dewey, 1910). Freire (2000) draws from these two schools of thought and in Pedagogy of the Oppressed, describes education as the practice of freedom and defines praxis as "reflection and action upon the work to reform it" (p. 53). Giroux (1986) agreed with Freire's description of the purpose of education and reframed his initial thoughts of schools as only social reproducers of the status quo, to seeing schools as sites of resistance as well. True education, includes an important synergy between teaching and learning where the process begins with unlearning, moves to learning, and ends with reflection and evaluation (Darder, 1991; Giroux, 1986).

Each of these elements of critical pedagogy has a direct application to the classroom setting in the development of relevant, real-world curriculum that challenges traditional thought. The process of unlearning, learning, relearning, reflection, and evaluation becomes the framework for meaningful professional development in the context of building FLCs that ultimately takes the same frame into each instructor's individual classrooms. One concrete way to operationalize critical theory in the classroom is through the use of culturally relevant teaching and pedagogy. 


\section{Culturally relevant pedagogy}

The roots of culturally relevant teaching came from a push toward multiculturalism after the civil rights movements of the 1960s. After the historic Brown vs. Board of Education decision in 1954, communities of color demanded that the curriculum be representative culturally and ethnically and that the students in these communities deserved the same education as their white counterparts (Sleeter, 2005). Integration of schools was a good first step: now communities wanted to see themselves represented in school curriculum. These arguments countered the notion that cultural and linguistic diversity was a deficiency and replaced it with a strength and empowermentbased model that communities of color believed should be central to learning. As Sleeter (2005) notes, "Multicultural education has served as an arena for working on schoolrelated equity and social justice issues from vantage points of historically marginalized communities" (p.11).

Teaching with a culturally relevant lens suggests an integration of personal, moral, social, political, cultural and academic knowledge and skills taught in tandem (Gay, 2000). Within this framework, students are taught positive ethnic identity orientations while learning about the contributions of cultures outside their own. The link between culture and instruction comes from research and evidence that cultural practices shape cognitive structures and that context both inside and outside the school is vital to engagement and retention of course material (Ladson-Billings, 2009). Encouraging faculty to engage themselves in thinking about their teaching in a culturally relevant way 
also has the potential to shift faculty thinking about their own identities.

Also, critical pedagogy embodies the basic philosophy that culture shapes student learning. Gloria Ladson-Billings (2009) describes it as "an approach that empowers students intellectually, socially, emotionally and politically" by explaining the dominant culture while valuing the student's culture (p.17). At the core of the theory, lie principles of social justice and reflection for the educator and the notion of equity for all students. This theory of teaching and learning refutes assumptions that students of color simply lack the academic prowess to be successful in mainstream schools. It emphasizes collective consciousness and community empowerment, not simply individual achievement. Undergirding the theory are three main criteria: students must experience academic success, students must develop or maintain cultural competence, and students must develop a critical consciousness through which they challenge the status quo of the current social order (Ladson-Billings, 2009).

Derived from critical theory, teaching through a cultural lens utilizes specific teaching strategies and paradigms of thought when interacting with students. A culturally responsive educator acts as a cultural mediator, a cultural organizer and orchestrates social contexts for learning (Gay, 2000). The educator communicates high expectations to all students, based on the genuine belief in the ability of students to achieve. They employ active teaching methods and develop student-centered learning opportunities, allowing students to help craft curriculum. This leads the educator to act as more than a teacher; the instructor becomes a guide, mentor and facilitator within the classroom walls. 
At the heart of instruction, is a deep commitment to uncovering the strengths that culturally and linguistically diverse students bring into the classroom and there is a concerted effort to dialogue with students, parents, and community members on important issues.

The culturally responsive educator exhibits sensitivity, which translates into engaging curriculum opportunities and knowledge, based in deep-rooted cultural values and social situations for learning. This requires the teacher to relinquish complete control over the classroom and gives students the chance to contribute to the discourse and organize in small learning groups that aid in the development of academic language (Darder et al., 2008). With each of these modifications, the teacher moves from what Freire (2000) called the "banking system of education" in which students are simply passive consumers of knowledge, to a system in which knowledge is shared, is more central, and they play an active role in their own learning (hooks, 1994). This shift requires the educator to be self-reflective and understand that "culture counts, conventional reform is inadequate, intention without action is not sufficient, there is strength in cultural diversity and test scores and grades are symptoms, not the causes of achievement discrepancies" (Gay, 2000, p. 20).

The theoretical framework often gets translated into the classroom in a myriad of ways. Gay (2000) culls together examples of responsive teaching as they relate to theory, pedagogy and practice in the classroom. She discusses culturally responsive teaching as education that acknowledges the cultural legacy of students, builds bridges between home 
and school and utilizes a wide variety of instructional strategies. It also legitimizes individual cultural heritages and incorporates multicultural materials in every subject area. Her primary focus is on the educator as a facilitator of shared knowledge. The role of the educator is to create a sense of belonging in the classroom by honoring students and promoting individual self-concept (Gay, 2000). Ladson-Billings (1995) also argues that culturally responsive methods are just good teaching. She notes that while traditionally undeserved students fare better in non-traditional classrooms, all students benefit from a more integrated and relevant curriculum.

In a study of eight effective teachers of African American students, through elementary classroom instruction, Gloria Ladson-Billings (2009) finds that students who participated in a larger effort to promote academic excellence performed better in school. Through teacher interviews, classroom observations and personal reflections she proves that intellectually rigorous curriculum that requires students to critically think about issues in the world, promotes success. She also notes that integrating students' cultural and social backgrounds gives relevance to the curriculum and promotes pride and selfrespect individually and within peer groups. When talking to the students, she explains that they found a support system in one another and acquired skills, related to one another well and held high expectations of themselves and their peers (Ladson-Billings, 2009). These same concepts, when applied to faculty communities, could yield similar results in terms of increasing faculty success in the classroom. Her writing looks from the perspective of both a teacher and a researcher, which lends to her credibility in analyzing 
and interpreting the qualitative data she gathered in her work.

Nieto (2003) explores culturally relevant teaching as a method to counter issues of equity and access. She views the theory more broadly: as antiracist education, which should be basic and accessible to all students. Her work focuses on her experiences teaching educators who go into diverse classrooms to move beyond the token multicultural lesson. She calls for honesty and inclusiveness in the presentation of content and emphasizes that students need an educator who will critically reflect on their methods. She encourages teachers to move past the deficit model that portrays minority children as liabilities rather than assets. Her argument is that all children need culturally responsive education to exist in the diverse world they are growing into (Nieto, 2003). An emphasis on high expectations while providing support to struggling students furthers the equity agenda (Oakes \& Lipton, 2002).

\section{Essentialism}

In order for faculty members to truly transform their teaching practice, they must be open to unlearning the assumptions and biases they bring to the classroom, and requires significant changes in the ways instructors see their roles and responsibilities. School systems, as they exist now, promote individualism over collective knowledge. Even for faculty that claims to use a social justice lens when teaching, deep-rooted beliefs about diversity become apparent in important ways. One of these ways is through essentialism. Employing an essentialist frame means that someone is attempting to reduce indigenous people to an "essential" idea of what it means to be African-American or 
Latina, for example. Spivak (1988) speaks about how the dominant culture (namely colonizers) works so hard to classify native communities as the "Other" that the communities often become silenced, meaning they do not speak up when reduced to generalizations. She explains that while this process can silence people, communities often engage in strategic essentialism, where they distill themselves to have control over the image that is presented of their community (Spivak, 1988). Minh-Ha (2009) discusses ways communities counter essentialism, by defining the differences between people as a result of infinite layers; that the notions of pure and true self are outgrowths of western dualistic thinking. She goes on to say that categories of people are fluid and changing and that attempts to place people in one "authentic" self, can rob communities of differing concepts of identity and place (Minh-Ha, 2009). Essentialism often surfaces in conversations about faculty diversity, reducing impressions of who would be the most effective teacher to instructors who may share characteristics of their students. This is a delicate issue that must be addressed carefully, as it should not take away from the need for all faculty members to improve their instruction.

\section{Critical reflection}

One final piece that proves critical for transformation of faculty is the integration of deep critical reflection. Dewey (1910) borrowing from philosophers Plato and Lao $\mathrm{Tzu}$, describes a reflective process, which is active, and deliberate that connects ideas that take into account underlying views and assumptions. This type of reflection also allows for confusion, doubt and acknowledgement of complexity before garnering a solution for 
an important educational issue (Dewey, 1910). Also, ethical and moral considerations, judging the equity of particular classroom activities and structures, and situating personal action in the larger social and political context, become important parts of the depth of personal analysis and transformation. The purpose of engaging in reflection is to develop the capacity of teachers to think critically about students and their learning (Minh-Ha, 2009).

A few different traditions in educational training further define the purpose of critically reflective practice. First, academic tradition forces educators to understand (Shulman, 1986). This shift in expertise is often fraught with difficulty in translating complex concepts into relevant and usable pieces of information for students, further explaining how reflection in community can act as a medium to tackle this task. In addition to the academic tradition, there is the social efficiency tradition, where educators read and attempt to apply best practices based on research. This involves reading and reflecting on practices that researchers deem effective and critiquing them when applying them to the classroom (Dill, 1990). Finally, there is the social reconstructionist tradition, which builds upon ideas put forth in critical and culturally relevant pedagogy where teachers are asked to change their own practices to counter the reproduction of societal norms based on unjust relationships of power and oppression (Carr \& Kemmis, 1986). Each of these traditions reinforces the argument that critical reflection plays a key role in transforming instructor behavior in the classroom. 
In recent years, self-study of teaching practice has found its way into much professional development. It goes beyond what the students learn and incorporates the processes, ideas and assumptions an instructor makes when making a decision to act in their classroom (Bernacchio et al., 2007; Finlay, 2008). Faculty that participate fully in a FLC moves issues of practice from a solo space, into a more public space and gives the opportunity for faculty to reflect in community (Jenlink \& Jenlink, 2008). This level of critical reflection on one's teaching practice can leave faculty feeling vulnerable and in conflict with their prior beliefs and practices about teaching and learning (Major \& Palmer, 2006). It takes deep trust and openness to transforming as well as critical dialogue sparked through reflection to better understand where our limitations are and how to shift to improve our practice (Johnsen, Pacht, van Slyck, \& Tsao, 2009; Palmer, 1997; Shor \& Freire, 1986).

\section{Conclusion}

Mezirow (1997) describes a transformative learning environment as one in which those participating have full information, are free from coercion, have equal opportunity to assume various roles, can become critically reflective of assumptions, are empathetic and good listeners, and are willing to search for common ground or a synthesis of different points of view. There needs to be a space where faculty can struggle together, and fail or succeed together. To build on Mezirow's definition, in order for higher education faculty to undergo transformation in their teaching practice, three major components have to be present in their development. First, there needs to be a sense of 
Chapter Three: Methodology

\section{Iritroduction}

This chapter details the study's research methods. It begins with a discussion of the study design, including a community-based participatory research (CBPR) approach, which I developed to honor my commitment to the development of shared knowledge with expertise coming from many different places (Darder, 1991; hooks, 1994). It then presents the qualitative methods used to collect and analyze data, followed by an exploration of the role of the researcher, the research questions and criteria for participation in the study. Finally, the chapter ends with ethical considerations, data collection procedures and specifics of data analysis.

Design

The Metro FLC is a long-duration advanced learning community with equivalent programs at SF State University (SF State) and City College of San Francisco (CCSF), in which students work together as a cohort over three to four semesters with a number of extra supports. Faculty members that teach and engage in professional development within Metro come from two different academies; one situated in health and the other in early childhood education. Participants for this study teach in either academy (a few participants teach in both) and represent both institutions. Six faculty members teach at CCSF, seven faculty members teach at SF State and two faculty members represent both institutions. Six faculty members in this study teach in the Metro Academies of Health, four teach in the Metro Academies of Child Development and five participants represent 
community with faculty, where questions can be asked and answered, identity explored, and solutions worked on with the purpose of changing instruction. There needs to be an emphasis on culturally relevant teaching, grounded in critical pedagogy with the understanding of systems that stifle student learning and promote inequity in education. Finally, there needs to be a strong element of critical reflection, which allows instructors to focus on personal growth within the context of political and social structures of education present on a daily basis. With the juxtaposition of these elements, faculty development moves from being only knowledge building around teaching strategies, to a more holistic perspective rooted in awareness and in action. 
both programs. For clarity, faculty members will be referred to in this study based on the institution where they hold the greatest amount of teaching time.

These study questions, which concern individual identity, experience and change over time, lend themselves to an in-depth, qualitative approach. Each of the fifteen faculty members completed a one-on-one interview of between 75 and 90 minutes in length. The interviews were audio recorded over a two-month period. They were then transcribed and coded for analysis. In addition to my own examination of the data, the four students from the advisory group also played a role in identifying themes. The advisory group made the decision to only have the student members look at the transcripts to get their interpretation, as I represented the faculty interpretation of transcripts. After an advisory group meeting on December 13, 2011, the students each took three to four transcripts of the one-on-one interview data and coded themes. Although we discussed a potential theoretical framework, the student researchers did not have an in-depth understanding of it or the relevant literature. Student researchers highlighted quotes and generated their own set themes they identified in the transcripts. These codes were folded into the larger index of themes that I created and added depth to the findings that I, alone, may not have identified.

This research design stems directly from the conceptual framework discussed in chapter 1 . The advisory group helped us to think collectively about how to best gather information from faculty and served as a way to reduce isolation, even for myself as the researcher. The expertise and wisdom that came from the students and faculty members 
who were advisors and provided a greater diversity of thought in the data collection, analysis and dissemination discussions. The individual struggle of developing a research study from start to finish became a collective one where all involved contributed and all benefited in some way. In addition, the use of the one-on-one interview technique allowed faculty the opportunity to speak candidly about their experiences in the FLC. Conducting a focus group might have added to faculty members' fears of being judged by their colleagues and the in-depth interviews allowed me to alleviate those fears through the relationships I have built with faculty. This study attempted to embody the principles of critical pedagogy and CBPR in the development of the research questions, study design and plans for data dissemination.

The Metro FLC began meeting four years ago, with a small group of faculty that spanned both institutions. I became the facilitator of the group one year into the inception of the group and have been working in that capacity since. Initially, the group was thirteen faculty members and has since expanded to include almost forty. In other evaluation efforts, we used a number of different assessment techniques to get feedback about the FLC, from faculty focus groups asking about experience in the Metro program, to a survey of faculty perceptions about the FLC as a whole, to written feedback after individual training sessions. Each of these tools gave us important information about the program and led me to look toward more in-depth qualitative methods when designing this study. Given the small sample size of forty faculty participants, conducting a quantitative analysis would not have yielded significant findings, nor would it have given 
me the kind of rich description that one-on-one interviews delivered. A fundamental component to the overall design and implementation of the study was the use of a CBPR approach to include the faculty and students in the process of planning, collecting data, analyzing the data and recommending avenues for dissemination of the research. This process is explained in more detail in the next section.

\section{The CBPR approach}

This study employs a CBPR approach to data collection, analysis, and dissemination. One of the hallmarks of CBPR is that the community is in the research process and recognizes the unique strengths that each brings (Minkler et al., 2002). The research questions put forth in this study developed from an ongoing formative evaluation of the Metro FLC over the past two years and will use the CBPR approach to benefit both the community of faculty and students. Key principles of CBPR include that all involved share a world view, have trust and mutual respect, share power, communicate and listen carefully, remain flexible, satisfy each other's needs and interests and have their long-range organizational capacities enhanced (Darder, 1991; hooks, 1994). This study attempted to use these principles through the development of an advisory group, who guided the study design and will continue to advise regarding the appropriate dissemination of findings. In addition, the group got excited about the research process and developed new research questions - unrelated to those addressed here - that we will continue to explore after this study is over. Finally, my own participation in the faculty community also was documented and included in the findings, 
which appear throughout this text in a different font (Cambria) than the remainder of the document (Times New Roman). This fits into models of action research, of which, CBPR is a part, where collaboration and inclusion of personal narrative is an integral part of the study design (Minkler et al., 2002).

\section{Advisory group selection}

It was important to select advisory group members from Metro students and faculty. Four students and two faculty members were recruited through personal contact and were selected for a number of reasons. With regards to the students, given that they would be seeing data from faculty members they knew, it was necessary that they be students who already completed the Metro program. Out of a possible 100 students who are Metro alumni, I endeavored to select students that had a lasting relationship with me and the program, and had an interest in research long-term, to make participation in an advisory group worthwhile for them. Each of the four students I approached accepted right away; three of them are SF State students and one of them is a CCSF student that has since transferred to SF State.

Arai Buendia and Ann Marie Davidsen are third-year health education majors, with plans to go on for graduate school once done with their undergraduate degrees. Edgar Velazquez is a third-year biology major who wants to go to medical school. Hermann Bormann is a third-year social work major who completed his general education requirements at City College. All four of these students completed the Metro Health program and decided to participate because have a deep interest in conducting 
their own research project during their fourth year at SF State. Thus, their involvement in the advisory group furthered their understanding of the research process. This was an important component of the CBPR approach used in this study; that each member benefited as much as they contributed (Minkler et al., 2002).

The faculty participants in the advisory group were involved with the FLC, but to this date, have never taught a class in the Metro program. For this reason, I was not able to use them as interview subjects; however, I knew that their unique expertise around the FLC would help shape the study. One faculty member, Ms. Cynthia Fong is from CCSF and the other, Dr. Amy Conley Wright is from SF State, providing a balance of perspectives between institutions and both represented Metro Early Childhood Education. The advisory group participants were selected with mindfulness towards benefits for the members of the group as well as expertise to bring to the study. Both women played an active role in determining content of the FLC trainings and continue to influence their home departments to spend more time and energy on training their teachers. Both Ms. Fong and Dr. Conley Wright hold important leadership positions in their departments and have considerable influence over their colleagues. Table 1 shows their names and affiliations. 


\begin{tabular}{|l|c|c|}
\hline $\begin{array}{l}\text { Name of Advisory } \\
\text { Group Member }\end{array}$ & Type of Participant & Institutional Affiliation \\
\hline Hermann Bormann & Student & CCSF transfer to SF State \\
\hline Arai Buendia & Student & SF State \\
\hline Ann Marie Davidsen & Student & SF State \\
\hline Cynthia Fong & Faculty & CCSF \\
\hline Edgar Velazquez & Student & SF State \\
\hline Amy Conley Wright & Faculty & SF State \\
\hline
\end{tabular}

Table 1: Advisory Group Members

\section{Role of advisory group in study}

The tasks of the advisory group included: developing questions for interviews, assisting with preliminary data analysis, acting as feedback loop for study and question relevancy and assisting with plan development for data dissemination. I met with each of the participants one-on-one at the start, to explain the project and organize schedules to meet as a larger group. This group of six met four times all together (once in summer 2011, once in fall 2011 and twice in spring 2012), each time examining different aspects of the study and offering expertise. A sample meeting agenda and follow-up notes appear as Appendix C and D.

The advisory group played an important role in validating the qualitative interview. All questions were vetted through this group and piloted with other Metro faculty, who were not involved in the study. The results of this study will not be generalizable as the Metro program is specific to CCSF and SF State and do not represent the general population of faculty at either campus. However, these interviews asked participants to talk generally about their experiences as teachers in post-secondary 
institutions as well specifically about their experiences in the Metro FLC. As a result, the findings from this study have the potential to be transferable to other institutions or programs looking to support faculty and develop an FLC (Herr \& Anderson, 2005).

The CBPR approach enhanced participants' ownership of the study and had implications in the direction of the future FLCs. One of the tenets of a CBPR approach is that co-learning and capacity building are central to every stage of from developing the research question to data dissemination (Minkler et al., 2002). This learning permeated the advisory group meetings even to the extent that the student participants had a say in the coding of the qualitative interviews, which will be discussed in more detail below.

\section{Interview participant selection}

Faculty participants in this study came from two different institutions and spanned six departments, allowing for a varied perspective on faculty development and teaching practice. Ethnic studies, health education, child development, English, communications, and mathematics were all represented in both types of data collected. These participants $(\mathrm{N}=15)$ were drawn from a group of 39 existing FLC members of the Metro Health and Metro Early Childhood Education programs. Faculty were selected for participation in the one-on-one interviews based on the following criteria: they must have participated in the FLC for a minimum of two years to be eligible as the interview protocol focuses on their work before and during their participation in the FLC, and they must have taught at least one course in the Metro program given the study's focus on teaching practice. Currently, 15 faculty members (including myself) met this criteria and each of them 
completed an 85-90 minute interview over the span of two months. The interview protocol and demographic questionnaire appear in Appendix A and B.

\section{Demographic Data}

Before conducting each interview, each participant completed a demographic questionnaire and the data that follows is a description of the faculty participants engaged in this study. Six participants work primarily at CCSF, five work primarily at SF State and four work equally between both institutions. On average, participants have been teaching 9.4 years, with the range between two years and 20 years. Faculty participants teach an average of three courses a semester, with the CCSF faculty teaching, on average more courses a semester than their SF State counterparts. A full-time load for faculty at CCSF is between four and five courses a semester (depending on the department) while a full-time load for faculty on the tenure-track at SF State is three courses a semester.

Seven out of fifteen faculty members are full-time and tenured or on the tenuretrack at their respective institutions, with one faculty member working a full-time load as a lecturer but with intention of seeking tenure. The remaining seven faculty members are part-time instructors, teaching two to three courses per semester. This difference in status is important to note, as there are expectations of full-time faculty that do not exist for part-time faculty, yet they have greater job security - although this difference in status was not the focus of the present study. The faculty participants in this study received payment for their work in the FLC. Each received a $\$ 500.00$ per semester stipend for four 
semesters of participation (or up to two years) in the community, regardless of part-time or full-time status at his or her institution.

Most of the Metro faculty participants in this study are female, with twelve participants identifying as female and three identifying as male. The faculty participants demonstrate linguistic diversity in that more than half speak a language in addition to English. Outside of English, Spanish is the most spoken language, with faculty members speaking Arabic, Chinese, Farsi, French and Hindi. Faculty members come from a number of different racial and ethnic backgrounds. Faculty members identify as Latina (Mexican, Peruvian, Colombian), Arab (Palestinian and Lebanese), Iranian, South Asian (Indian), East Asian (Chinese) with the majority of respondents identifying as White. Nine out of the fifteen faculty participants have mothers who have a college or graduate degree and twelve have fathers that completed college or graduate school. The following section describes how data was collected.

\section{Data Collection and Analysis}

One-on-one interviews were done with all eligible faculty participants. These interviews were geared toward answering the research questions and getting a first-hand account of faculty experiences in the Metro FLC. The interview protocol was vetted through the advisory group and was piloted with the two advisory faculty members, prior

to use. The advisory group suggested that I simplify the questions to fall into three major areas. Honoring the stories of each of the faculty members, the categories shifted from a deep focus on where faculty participants came from and how they got into teaching, to 
asking about teaching careers and philosophies around teaching, actual classroom teaching practice (where I ask about engaged teaching, as defined by the faculty) and the ultimate impact of the FLC on their teaching. Interviews were digitally recorded and transcribed, and the transcripts were entered into Atlas. Ti. They were then analyzed and coded for salient themes with student members of the advisory group present to learn qualitative data analysis skills along with me and to offer suggestions for codes.

\section{Role of the Researcher and Context}

I am a member of the community of faculty being studied in this proposal, which adds an insider dimension to the whole process. While I would like to say that we are all equal colleagues in the community, I am the only member of Metro that is paid to develop and lead the FLC meetings. I need to honor my place in this research and consider who I am and what I represent as a part of the CBPR approach to this study. I cannot fully separate my roles as the faculty lead, participating faculty, and researcher, and therefore I acknowledge them here. I also attempt to highlight my unique selfreflection throughout my writing. As Lorde (2007) describes: I find it necessary to scrutinize the words that I write, as well as my place in this dissertation and will do so as I continue on with this work.

Denzin and Lincoln (2007) talk about the importance of understanding one's place in the research process. There is no doubt that the research conducted in this study reflects my own personal values and experiences as the leader of this community of faculty. I am studying a community to which I belong, and I do not pretend to be 
studying the "Other" (Lorde, 2007). This approach challenges the dominant paradigm that says that researchers must play an objective role when studying and writing about communities. Current thinking about qualitative research calls into question whether complete objectivity is either, desirable or feasible as a goal (Denzin \& Lincoln, 2007).

One benefit of being an insider in this community is that I have been able to develop the relationships I need to collect data. My faculty colleagues have graciously offered their time and energy to this research and were given $\$ 20$ gift cards to the bookstore at the end of their formalized commitment. Because I work at both SF State and CCSF, I was able to make contact with faculty directly and am extremely familiar with both campuses. Most interviews took place on the campus in faculty member offices, in my office at SF State or in surrounding classrooms that were unoccupied.

\section{Research Questions}

This study aimed to answer the following overarching question: How do faculty learning communities affect higher education teaching practices? Three sub-questions emerged from the primary question: 1) What motivates people to teach in a faculty learning community? 2) What are the struggles that faculty members face in striving to be better instructors? and 3) How does participation in a faculty learning community influence teaching practice? In what ways do they have an influence?

\section{Ethics and Protection of Human Subjects}

There is a risk of a loss of privacy for participants engaged in this study. Keeping all research data in a secure location, away from the institutions, minimized the risk. 
However, no names or identities of faculty participating in the qualitative interviews will be used in any published reports of the research, with the exception of the members of the advisory group, who requested that their real names be used. The advisory group and I had access to the interview transcripts; however, I removed identifiers from those prior to conducting data analysis. All research data (informed consent documents, demographic sheets, audio recordings, transcripts) are kept in a secure location, and only I have access. Audio recordings were destroyed after written transcripts were created. These data may be used in the future only for research purposes consistent with the original purpose of the stated research about the influence of the FLC on teaching practice. Participants also had the opportunity to review transcripts to ensure that they have been properly represented. There are no direct benefits to the participants and there was no payment for participation. Participants engaged in the following steps in person, prior to engaging in the study. Before each interview, I,

- Informed the participants about the study procedures;

- Gave them an opportunity to ask questions and have their questions answered;

- Gave them as much time as they need to make a decision whether or not to participate and;

- Asked participants to sign an informed consent document.

I was responsible for answering the participants' questions and obtained consent signatures prior to beginning data collection. Participants received a signed copy of the consent form for their records. The following chapter details the findings that emerged as a result of data collection and analysis. 


\section{Chapter Four: Report of Findings}

\section{Overview}

Educators who challenge themselves to teach beyond the classroom setting, to move into the world sharing knowledge, learn a diversity of styles to convey information. This is one of the most valuable skills any teacher can acquire. Through vigilant practice we learn to use the language that can speak to the heart of the matter in whatever teaching setting we find ourselves in......we do the work of opening up the space of learning so it can be more inclusive, and challenge ourselves constantly to strengthen our teaching skills (hooks, 2003, p.43).

Four years ago, Metro faculty embarked on a collective journey to change and strengthen their teaching practices through participation in a faculty learning community (FLC). A once solo endeavor of teaching a class, behind closed doors with no space for discussion and self-exploration, moved from an individual effort, to a collective struggle. As hooks (2003) explains, the journey of becoming an amazing teacher is wrought with challenges, and yet, it is our job to work beyond the classroom setting. As articulated in chapter 1, the mission of the FLC is to engage in a constant process of reflecting and acting on improving teaching (and learning) for our students and this happens in a variety of ways.

The goals of the Metro FLC are to help faculty build community with one another (to create a similar support to the student cohort), examine teaching approaches grounded in critical pedagogy, take time to self-reflect and transform practice. In this chapter, faculty explore how their identities and philosophies as instructors motivated them to join the FLC, talk about their struggles and fears in being a teacher in higher education and delineate the influence the FLC has had on their teaching practices. 
As a reminder from chapter 3 , the primary research question of the project is how do faculty learning communities affect higher education teaching practices? Three subquestions emerged from the primary question: 1) What motivates people to teach in a faculty learning community? 2) What are the struggles that faculty members face in striving to be better instructors? and 3) How does participation in a faculty learning community influence teaching practice? In what ways do they have an influence?

The findings in this section break down into three major categories. First, the chapter discusses faculty members motivations to be a part of the Metro FLC. Second, there is a detailed set of findings that demonstrate the struggles that instructors face in working toward improving their teaching practice. Finally, the last section is an exploration of how faculty members believe their participation in the FLC has affected their teaching practices.

\section{Motivations for Entering Teaching and the Metro FLC}

As referenced in chapter 3, the faculty members that come to teach in the Metro program are diverse in many different ways. Study participants in the following section

talk about their identities as a factor in how they teach as well as their own experiences as a student in the past. They also discuss how their philosophy and belief in education equity, shape their interactions in the classroom.

\section{Faculty identity as a motivation}

Metro faculty entered teaching for a variety of reasons. A few faculty entered teaching because they felt they were called to it, a few entered tenure-track positions 
because of a love for research and the others entered teaching after careers outside academia. For example, one faculty member came to teaching after a career in journalism. Only two faculty members knew that they wanted to be teachers before entering higher education as an instructor; the majority worked other careers prior to entering the classroom. This makes the need for a FLC more pronounced as instructors do not have mandated training prior to teaching their first class.

Faculty identity came up repeatedly when discussing classroom practice. Many faculty members talked about how their own cultural and economic upbringing affected their classroom experiences. A CCSF faculty member talked about the impact her racial and gender identities play on her interactions with students. She discusses how the lenses of race permeate her worldview and that she wants students to not have the same struggles of dealing with racist faculty members and low expectations of her as a woman of color.

I am that other. Even when I think I'm not, apparently it turns out I am. So it's important to me because I need to make sure that other people would hopefully not have the same struggles; that we are questioned for who we look like before people figure out that there is an intelligent being behind our outward appearance that they have to be sensitive to. My whole undergraduate [education] was finding myself and figuring it out what it meant to be what I said I would be; someone of consequence, someone who was taken at face value for her intelligence, not because I had different color skin or because I was a woman.

A SF State faculty member talks about the impact of growing up as part of a family of immigrants, as a defining influence on her teaching. She goes on to describe how experiences she had in her family give her an understanding of how to frame some 
of the assets she sees in her students.

I was born and raised in a working-class neighborhood and had to go through barriers of growing up in that. But in addition, I had a dual framework where I had social capital because my parents came from a different country and they were educated in a different schooling system. I was able to relate with the working class students that I went to school with. I was born and raised in the city that I grew up in, but I also had the reference of [being] like I was out looking in which I think a lot of kids of immigrants do or could do... [Our students] have stories that come their parents that are totally different than their realities. So the racism, the sexism, all of that, you know, parents don't talk about racism when you're born in a country that's all your people. Even though there were other types of oppression, it was different. I was able to say [to my students], "You have the social capital; you have this cultural wealth and these other assets." Use these as your tools. Use these to view what the system is and see these inequalities."

I echo some of her views with my own story of growing up in an immigrant

household and explore the way in which that affected my views of my role as an instructor.

Growing up as the child of immigrant parents who struggled and fought for us to be accepted and educated definitely fuels my teaching. They didn't allow the racism that I felt going through school to be a reason I didn't succeed. Doing well in school was an expectation, as was continual engagement in the world. We were expected to know what was happening politically, even if my parents themselves didn't really engage directly. My mom is a teacher; she's a high-school chemistry teacher. And yet, I got a very White dominant education in a homogenous community. I want our students to know their history, to value their own worth and to know that their cultural heritage is beautiful, in a way I never got in school.

When asked about how their identities affect their teaching, two faculty members detail different visions of how they play a role. One faculty member from SF State talks about her hesitation to discuss her identity.

I know how my identity does affect teaching and my work. I think that I'm a little 
bit shy of actually communicating that out loud or explicitly saying it. And I think there are a lot of reasons for that. It's internalized stuff, institutional stuff and personal stuff. You don't want to be seen as the angry brown woman. My father was a refugee. My mom was refugee for a little while. They were basically kicked out of their countries because of war and oppression and injustice.

This faculty member is very clear that her identity impacts her teaching in a myriad of ways. Her own experiences with racism make her question how much of herself she brings to her practice. She engages often in reflection of how to express who she is to her students, and her own internalized struggles to overcome intense oppression she and her family experienced. A faculty member from CCSF explains how her own personal history opened her eyes to the inequality in the educational systems.

You are talking about White supremacy and the history of White supremacy. I usually tell that story to my students about how the New Deal, which was an absolutely segregated, lily White New Deal, put a lot of White working class folks on an escalator. You know, all the boys in my father's family, all the cousins they all went from you know factory type jobs to being professors with $\mathrm{PhDs}$ in one generation for free; they paid no tuition. They came home from the war and they all got $\mathrm{PhDs}$ and so they changed social classes. Our society doesn't like to talk about some folks going up on the escalator and that somebody else is standing on an escalator going down such as like a prison record where you are you know marked and you are stigmatized forever.

Her understanding of the privilege she has as a white woman teaching in an institution that her father benefited from directly, fuels her desire to not only expose issues of education inequity to her students, but show them that there are systems that allowed one group to benefit at the expense of another. One SF State faculty member talked about how her first teaching job at a community college brought her cultural upbringing to the forefront of her teaching career. 
It made me actually think about my cultural upbringing and really start bringing out a lot of what I didn't notice. I didn't realize some of the ways I was brought up are very reflective of how other people speak about their upbringing in more of a German background, so it was kind of interesting. I know I was getting in a rut with the way I saw students because I was starting to ask those big questions to [my] self you know, "Am I making a change?" I think for me, it was a shift in the perspective of how I view students, because I come from a context of growing up in a family that was extremely judgmental of others and it's been something I have always had to remind myself of stepping out of.

Her exploration of her identity shows how cultural norms in our backgrounds translate into our teaching practice. This faculty member noticed how those norms were difficult for her in her childhood and felt the need to consistently work to shift those when she works with students. A SF State faculty member talks about his childhood experiences influenced his desire to be an instructor. He speaks about his dad and how his family background had an impact on entering teaching at SF State as a career and on his love for learning.

They offered me this job but, and I was 24 I think at the time and my dad was like "Wait, are you nuts? You know you've got to go up there and work. You are 24 years old and you know I went through sixth grade." My dad is really smart loves learning, loves reading, loves history and reads like crazy. Now that he is getting older, he watches a lot of documentaries too, but that you know, he is like still veraciously curious and absorbs everything. He was excited about me being a teacher way more than he was interested in me being a journalist or anything else.

Faculty identity plays an important role in instructor motivation to teach and their philosophies about teaching in general, and yet, we often struggle with how to address questions that come up for us, in isolation. Who we are and where we came from influence our need to be in the classroom, our approach to teaching and our interactions with students in a fundamental way. At times, this gets generalized to the impact of 
particular characteristics (such as similar racial or ethnic backgrounds) on the students that we serve as part of Metro. Faculty members also talked about the importance of faculty of color in the classroom. The diversity of faculty came up in different ways, yet the outcome was the same for each faculty member; diversity matters. Faculty believe that their experiences and identities as (being a part of racial and ethnic minority groups or coming from low-income backgrounds, for example) allow them to connect with students differently than their counterparts who don't share these characteristics. Students should see themselves reflected (as much as possible) in the Metro faculty they see on a regular basis.

It is important to talk about [faculty identity and diversity] because there are a bunch of little girls and little boys that are going to see different things throughout their school. They should see men and women and African Americans and Mexicans and all sorts of people. They should see them everywhere, because we are everywhere. And yet, we aren't represented in academia; there isn't much of a variety. Why not, where are we? We are somewhere but where are we and why did we choose a different path? So I don't need everyone to be in academia but there are not that many minorities in academia.

One CCSF faculty member noted how different the connection was between her students, herself (as a white woman) and her teaching assistants, who were AfricanAmerican and Latina women.

Teaching with [teaching assistant] there was exciting. There were a lot of young black men in the class. I just think it's a completely different connection that she has with them and it is like so awesome to stand back and watch. There's a connection and its just like it doesn't matter if I am you know Jesus, Mohammed and the Buddha all at once. It's just a connection that is different.

This faculty member's assumed homogeneity of African-American and Latino 
communities uses essentialism to argue for the diversity of instructors as a whole. Making the claim that faculty of color as instructors connect better with student inherently, can lead to a dangerous generalization that trivializes the importance of solid instruction in all forms. As described in chapter 2, a person with an essentialist framework has the ability to silence marginalized communities and can allow faculty development leaders to maintain blinders when working to transform all instructors. Understanding essentialism forces me as the director of the Metro FLC program to think both about diversity as an important factor in faculty recruitment and selection into the FLC, and simultaneously cautions me to be careful not to be essentialist as we move together in community to shift teaching practice.

While many of us faculty members identify with the students we work with, we also know that we can't completely understand the context of their lives. This is related to our own personal upbringings, as well as the societal context in which students are engaging in higher education, which is vastly different from how we went through school. One SF State faculty member noted that she, "still struggle[s] with this commitment to equity and social justice and understanding the struggles of our first gen[eration] students." Understanding and struggling with our own questions of identity is the first step in analyzing where our philosophies of teaching come from. Yet, we have to be careful to see our students as individuals, with important identities and backgrounds of their own, that affect their experiences of learning as well. Faculty identity also tied directly into their lens of generativity. The construct of generativity explores how people 
have the desire to establish and guide the next generation (Erikson, 1963). Faculty members reflected on their own experiences of school and regardless of background, described them in two ways. Either they wanted students to have a better world that what they had (spoken by those faculty that came from less privileged backgrounds) or they wanted students to have the same opportunities they had (those that came from more privileged backgrounds). The next section describes how faculty identity and their past experiences of school intersect as motivation to shift or change teaching practices.

\section{Faculty past experiences of school as motivation}

Several faculty members talk about wanting to be a part of the FLC because they want students to have an equal or better education than what they as instructors have/had. A CCSF faculty member said, "I feel really lucky to have a liberal arts education and I feel like if I can just share one drop of the kind of freedom that I felt as an undergrad to explore with students, I believe that we can end cycles of oppression through education and social action." Another CCSF faculty member talks about how she feels about teachers that didn't push themselves to be better, causing her to spend a great deal of time reflecting on her own teaching.

I had disrespect for some teachers I felt weren't vigorous enough or challenging enough or got a little lazy. I remember even in grad school; I had a very intellectual, smart, challenging teacher who, in general, I really loved. In one class, about half way through the reader, everything started to be like 15 years old. All we could think was, "You know, she only updated the first half. She never got around to updating the second half." I lost a little respect for her because I wanted the rigor from her and I wanted it for me. What I hear from colleagues here at the college is that we do our students a disservice if we say, "Oh poor baby," and hold them to a lower standard. You know, that's a form of 
racism or a form of classism as well.

A CCSF faculty member talked about wanting students' experience in school to be better than what she had.

People assume [that I teach] because I'm a minority. Partly it is [the reason I teach]. I have lived in that world. I have had many experiences that make me feel that I need to make sure that the children who are coming up; who are like me would hopefully have a different experience than what I had; that they then would want to improve it for the following generation behind them.

The desire for faculty to replicate their own educational experiences (or improve on them, in some cases) comes from an understanding of the inherent inequity in higher education. Some faculty that mentioned wanting their students to have a similar education to them, went to elite private institutions and want their students at large, urban, public institutions to have the same privileges. Faculty members also talked about being interested in making their material fun, accessible and want to empower students to go out into the world to make real social change. A CCSF faculty member also talked about being excited to teach things that ordinarily are not seen as exciting by students.

I still like interacting with them and teaching them things that were really basic that they knew were really basic, but they just had never understood before. I think that's the most exciting for me; the class discussion. My second favorite thing or the most engaging thing is trying to make grammar or topics that are really not as exciting and possibly alienating, just because they're perhaps things that the students feel that they should know that they don't know. I get excited about teaching those in an exciting or unique way; using metaphor in different scenarios to help them get to an understanding of comma placement or dangling modifiers or whatever it might be.

A SF State faculty member reiterated this view of students as active participants in a social change agenda. 
I want them to think of themselves as agents of change. I want them to not just be passive observers either in the classroom or in life. If they are not ready to jump in now, they hopefully will develop some tools here and in other classes, in other places and other experiences where they will be able to later.

Another SF State faculty member summarized her view of how her identity and her teaching life come together in seeing her students as integral in her work in attempting to transform our society into a more equitable one. This intersection of individual identity and a desire for larger systematic change comes together for many faculty in a classroom full of students.

To me, a classroom is a sacred space, right? You're on. Teachers are actors in a way. You know you have to set the mood; you have to set the tone. So it's a sacred place. There's just a lot of work that goes into it. There are a lot of great things that come out of it. There are a lot of bad things that come out of it too. I think the exciting piece for me is being able to share that space especially, with people or young people that I see as my community. Young people that I see as, you know, my community. They're part of my larger community. They're part of me and my work and my work for an equitable society that they're part of that. I think that's what gets me excited to go in.

Understanding of the inequity in large urban educational systems, as well as the identity of each Metro faculty member fuels a desire for many instructors toward shifting teaching practices to be more student-centered. The classroom is where struggle takes place between identity and past experiences, and this is often done in isolation. The Metro FLC is another place where faculty get the opportunity to struggle with these components of themselves, but they struggle in community. Yet, there are significant barriers that prevent faculty members from engaging fully in transforming their instruction. One of the most significant barriers is fear, stemming from a lack of 
preparation to be a classroom instructor and a fear of judgment from colleagues when exposing our teaching struggles.

Fears of Faculty Members

Metro FLC instructors expressed a number of fears they have as teachers in higher education institutions. Faculty members struggle with feeling unprepared, as they often get very little to no training on how to teach. They have fear about what their colleagues will say about their abilities, and some feel like they may be uncovered as a fraud. They also struggle with feeling untrained to handle difficult conversations and issues that come up in the classroom with students. Their fears are described in this section.

\section{Fear of feeling unprepared}

Unlike teachers who enter the profession after studying to get a teaching credential, faculty in higher education (with the exception of a few that got degrees that had a teaching focus) do not engage in much professional development. This fundamental lack of training often causes faculty to feel uncomfortable in the classroom and unsure of their abilities to handle difficult situations (Johnsen, Pacht, van Slyck \& Tsao, 2009).

Several faculty members mentioned that without the Metro FLC, they would have no other forms of professional development in their lives. They do not get structured time for faculty collaboration in courses, or to even talk about teaching and pedagogy as part of standard university or college schedules. One faculty member described his/her experience of professional development - or lack thereof - at CCSF in the following 
way. "You've heard me say in the 14 years before Metro, maybe I had 45 minutes or something on pedagogy. I mean almost nothing. That's the sad state of affairs.” A faculty member talks about a similar situation at SF State.

I can count on one hand the time we've had meetings here at the department-level or at college-wide level where we talk about pedagogy, where we really get into one another's practice. I would look forward to some of [our Metro FLC] meetings because the agendas were really enticing. We are going over bell hooks or we are going to talk about these issues; we are going to have an honest discussion.

This lack of professional development adds to fears that faculty needed to address as part of the FLC. They need more tangible activities to use in their classrooms, help addressing feelings of being unprepared in front of students, more time for course infusion and a strong desire for more of a focus on critical pedagogy and critical race conversations as a large group.

One SF State faculty member talked about not feeling competent to make students feel comfortable and welcome in her classroom. She described struggles getting to know each individual student, given her large classes of students. She talked about success in getting them to talk more to each other, but the management of group activities is something she still wants support around. Another SF State faculty member reiterated the difficulty both in managing group activities and just generally feeling unprepared and adds that the workload is crushing. Teaching multiple composition courses, he said that he is constantly looking for ways to streamline the grading process. A few faculty members at CCSF also said that teaching five classes a semester, it is tough to keep up 
with all the things she wants to do for students. There simply aren't enough hours in a day, yet there is still a strong desire for time to collaborate and struggle with fellow instructors, even if it takes time.

Faculty members struggled with wanting to take more risks together, as mentioned by a CCSF faculty member. She explained, "Perhaps it would be nice to push the envelope further, in terms of taking risks together, or creating something together, which would have deepened the relationships we have with one another, beyond the professional level." She wanted to see faculty come together to explore times in the classroom that were messy, or when things didn't go well. In addition, this faculty member also said that she wanted to have the opportunity to get to know her colleagues outside of the meeting space. Social events, classroom visits, would have helped her get to know people on a more personal level. This would have deepened trust and might have allowed faculty members to be more vulnerable with one another; might have alleviated some of the fear that came from being unprepared.

\section{Fear of inadequacy and fear of judgment}

Faculty members talked about worrying about feeling judged, and some talked about a fear of being exposed as a fraud in their profession. These fears played an important role in fueling faculty desires to become better instructors, while at the same time, can paralyze instructors and hold them back from improvement. The ego in teaching often allowed faculty to be open to change, but at times, prevented them from becoming vulnerable around their peers (Johnsen, Pacht, van Slyck \& Tsao, 2009; 
Palmer, 1997). They wanted to improve their teaching practice, in part, because they didn't want to appear incompetent.

I often think to myself that being a teacher is one of the most important responsibilities someone can have in the world. You have the opportunity to shape young life, to shape minds and to empower and influence people in a way that I don't think you have really any other profession. I worry that I'm not living up to that responsibility. I worry that I am not capable of inspiring and empowering students, or that I think more of myself than is actually there. It's a tricky thing, the ego when it comes to teaching.

There also was a feeling of intimidation; that they were simply not as good as other instructors at the university or college. The FLC became a place that was simultaneously a safe place to be with colleagues and a place where faculty feared judgment from peers.

I fear judgment from others. It's like [judgment] was so easily given out. If people give it out so easily, I don't want to be receiving it. I have been doing a lot of selfexamination from the [faculty learning] community around that because I hear every one else and the way they think about students and I'll sit there and go, "Wow, that is not at all how I was viewing that situation."

The fear of judgment in this faculty member appeared to silence her in FLC meetings. She chose not to express how she was truly feeling, out of fear of being seen negatively by her peers. She also talked though, about how much she learned from her colleagues and in this way, her fear helped propel her to a deeper level of self-reflection. A CCSF faculty member described feeling out-of-place within the Metro faculty group. She said, "I joined the FLC after the group had been meeting for a year, and I think it took me a few meetings to really feel a part of the group. At times, I have felt both inspired and a little intimidated by the more experienced faculty in the groups." 
A SF State faculty member talked about feeling exposed and that he even after teaching for a number of years, he still feels like he might be seen as a fraud.

I told you at the beginning of this interview that I came in to this all by accident and that I didn't have a pedigree that other people have. Sometimes, just sometimes, I feel kind of like a fraud you know? These are some smart people around here and they articulate the stuff way better than I can. I know they are so much more professional and well suited in the classroom than I am. I am a jokester, inappropriate and I talk about ridiculous things. I would never have shared [some of those things] with the learning community. I joke, not as a way to get students on my side but because that's my personality.

A SF State faculty member expressed her desire to participate in the FLC, but struggles to find her voice among more experienced faculty members. Faculty talked about the pressure living in the Bay Area, to be involved with activism outside of the classroom and there was some competition around the types of activism people engaged in. Often, faculty members would talk about their engagement with non-profit organizations and protests during the upcoming weekends, and it caused some faculty to be conscious of their own activist work. In addition, faculty worried about saying the "wrong thing" in the meetings. As they attempted express their concerns, faculty were afraid of being judged or seen negatively and were afraid of not being supported in the group setting. One faculty member describes how it took her time to feel like she could really speak up in a setting with her peers. She says,

I think I'm starting to find my voice a little bit more in the larger system. I think for a while I was too afraid to say anything because I felt like, "Do I know anything?" and "Do I know the right to say or the right thing to do?" You know and I think I was a little intimidated at first so I think the more I build up my confidence and like who I am as an instructor, the more I will be changing in different ways. 
The issue of vulnerability and insecurity came forth when addressing the way a community interacts and becomes even more pronounced as we move the discussion into talk of critical pedagogy and the classroom.

Fear of inability to operationalize critical pedagogical principles

One aspect that came up in many of the interviews was a need for more targeted understanding of how to operationalize critical pedagogy in teaching practice. Faculty felt ill-equipped to handle difficult conversations, classroom struggles and how much of their own beliefs to bring in to their teaching. Critical pedagogy offers multiple avenues for exploring the world. It starts with an understanding that knowledge is socially constructed and we exist in a world that is full of contradictions and inequality of power and privilege (Darder, 1991).

Faculty members at both institutions talk about how difficult it is to talk about structures of oppression in the classroom. A SF State faculty member said, "As a white male, I have a hard time talking about race and gender in the classroom. I don't think I create lessons around it, to be honest." One CCSF faculty member said, "I find that sometimes like even though I'm always reading about or trying to learn more about how systems of oppression work, I find it harder for me to go from learning more about systems oppression to changing teaching practices." Another faculty member discussed the struggles she has not only in the classroom, but also with other faculty members in having difficult conversations. This echoes the earlier finding about how the FLC can be 
a place for support, but can also be a place that does not assist faculty in using the space to go deeper in thinking about critical pedagogy.

I've had conversations with people that I felt comfortable enough with, like you. You know you've called me out saying, "When you say this, this is what it does to me." And I felt like we needed to have those types of conversations first, but then what does it trigger? How will I be able to say, "No, that you are a good person and you didn't mean to offend me when you said this," but how to have that kind of conversation that explores what it feels like and brings out for people. That's tough.

The fear of opening up difficult conversations came forth as a struggle; faculty wanted to be able to have these discussions, but did not have the tools necessary, or the time with colleagues to explore how to do this in a thoughtful way with students. In addition, some faculty felt that students were not prepared to take on some of the control required to engage more fully with their educational process. Using critical pedagogy to transform the classroom requires instructors to shift their own thinking about how faculty/student dynamics occur. A SF State faculty member discusses that using critical pedagogy in the classroom requires students to be open to learning in a different way than they are used to learning. Another SF State faculty member talks about how even the construction of knowledge is a political act and requires paradigm shifts among multiple parties. He discussed his first few years in teaching and how his training in social sciences did not prepare him to explore the kinds of issues that being a part of the Metro FLC did. He described his perception that knowledge was seen as a closed system, where the instructor generated knowledge and students were simply the recipients of that knowledge. 
I didn't really question the politics and a lot of the underlying values and assumptions in knowledge. And I was trained as a social scientist but was really not trained to look for power issues, political issues in the production of knowledge and in the dynamics in the classroom all that much. So it was a very naïve kind of view like, "Everybody is excited." That really, if you just work with everybody, then people will do well. There is so much more to it.

A CCSF faculty member talked about identity politics and how the race of the instructor plays an integral role in opening students up to important conversations.

When you have a couple of authority figures and one is a woman of color or a person of color and one is a white person, I think its just interesting how it works. It becomes like you are not anti-white if you talk about white supremacy. I think there's so much tension and you know I see that sometimes like a young Black man will say, "Well Congress is basically like a White meeting" and then I watch the white students get totally uptight and feel threatened like someone is criticizing them. That's where my identity in supporting the young Black man is important. They see a white instructor talk about white supremacy.

Yet, faculty feel under qualified to have the types of discussions alluded to in the quote above. One SF State faculty member mentioned that the FLC was the first time she ever had conversations about resiliency, power dynamics in the classroom, or socially relevant curriculum. She noted that it was important to keep talking, even as conversations often made her feel uncomfortable in a room full of her peers. These fears influence how willing faculty members are to engage in an analysis of the world with their students that echo their social justice principles. The Metro FLC proved to be a space that helped faculty address some of these fears and began to move them toward a more reflective practice.

Positive Influence of the FLC: Addressing the Fear through Collective Struggle

Faculty members felt that they gained a number of important things as a result of 
participation in the Metro FLC. A CCSF faculty member said that in helping her address some of her fears, "The faculty learning community has become far more important to me than I ever realized that it would." She described the importance of relationships she built, time for collaboration with colleagues and appreciation of strong facilitation where she got to learn and share new teaching techniques, content and assignments. She also engaged deeper with questions of privilege, identity and power in the classroom, questioning why they took certain approaches with their students. Faculty asked themselves questions, such as why they were such sticklers about taking attendance, why students didn't come and see them during office hours and what they could do to connect with them in a more authentic way.

\section{FLC builds skills and tools}

One important aspect of the FLC is that it gave faculty tools and practical strategies to use in the classroom. Sessions were set up so that conversations faculty had about education equity were structured in the same way they could be used with students in the classroom. Training sessions included active learning, where faculty learned how to engage students through games, small group discussions, and interactive activities, such as showing only portions of films and stopping to ask students to reflect and ask their own questions of what they are seeing. Faculty looked at case studies of organizations doing work in communities, and learned strategies to get students to read in depth, including a jigsaw (where students break up the reading and teach each other) and talking back to the text (using written words and questions in the margins). The modeling 
of teaching practices by the facilitator seemed especially helpful. One CCSF faculty member described the importance of open facilitation, where the needs of the faculty get integrated into the training session in real-time that demonstrates openness to the experience in the room and flexibility with curriculum. For example, the facilitator may want faculty to talk about how to develop deeper questions to ask students, but the faculty had a particularly difficult class session, and wants to know how to address a disruptive student. The training would shift to include assisting this faculty in handling their student concern.

You really allowed conversations to take us to places which I think you hadn't anticipated and were really okay with restructuring our time to allow those conversations breathing space which was practicing best practices yourself, right? I thought that you did that really well and I think that people really appreciated those discussions. You know, you are really good at letting other voices in.

A CCSF faculty member gets specific about what particular techniques she uses now, as a result of sharing in the FLC. She uses a technique called a gallery walk, where students divide up a particular reading or lecture and put bullet points of the important ideas on a sheet of butcher paper. Then, the students walk around the room, looking at the papers and making their own written comments below the group's text.

Well, one thing I like is that you're modeling stuff. I think that modeling or demonstrations of techniques are extremely important. I'd never heard of the idea of small groups with butcher paper and it doesn't get better than that. I do think if we could say there are eight techniques that everybody needs to know (the jigsaw, the line up, the spectrum, drafts on butcher paper followed by gallery walk). Those are very valuable.

That same faculty member describes what she sees as the warm classroom 
atmosphere, which she saw modeled in the FLC. A combination of modeling behaviors and strategies we want to see in the classroom, and direct instruction about some that faculty may not have been aware of proved successful. Some key elements of the FLC were providing food to faculty members, as an appreciation of their participation after a full day of work, including colorful tablecloths and music as a way to encourage creative elements into the classroom. Each faculty was greeted by name and gave him or her many opportunities to provide feedback that was then incorporated into a future meeting. These were modeled in a way that faculty felt that they could do similar things in their own classrooms with students.

I understand and use name plates, and frequent feedback to students now more than ever. I am focused more on greeting each of my students individually and work hard to ensure that my room is democratically set up (in a circle, where everyone can see one another). These seemingly small things make a huge difference when trying to operationalize my social justice ideals in a classroom.

Most faculty members interviewed also felt that repertoire of tools and techniques, had been expanded as a result of the FLC, as described above. Using name cards to get to know students names with the inside of the card having boxes where students provide daily feedback to instructors and got comments from the faculty member in return, proved especially important.

The FLC has helped me and my colleagues do something different. It's still active learning and engaged pedagogy, as we call it now, but I think that's been good because it has really enforced how important it is to have group work. It's reinforced how important it is to mix it up and the little strategies that we get, like the name cards. That is something I can't ever imagine like not being part of my teaching practice ever again. 
These shifts in approach to classroom instruction, as well as changes in identity for faculty members proved important reasons why the FLC continues to be a space for struggle. In addition to gaining practical skills and techniques for use in the classroom, faculty members discussed the intellectual shifts they went through, in rethinking particular aspects of their philosophy on teaching, even down to the classroom setup.

\section{FLC allows deeper engagement with critical pedagogy}

Curriculum integration with structures of oppression, such as racism, classism, sexism, and homophobia and ways students can change and engage with these systems proved to be an important, yet a challenging part of teaching and learning in the Metro FLC. A CCSF faculty member talked about her experiences with the FLC as a space that helped her integrate these structures into her curriculum. It helped her to shift how she thought about oppression and made her talk about it more intentionally in her classroom.

One of the things that Metro has done is help me integrate more of the social class issues, in addition to maybe racial and ethnic issues, religion and sexual orientation to a degree, but I would say they've really helped me with the social class issues. I felt like that [deeper conversations in the FLC] were really helpful to stimulate thinking about different paradigms in teaching.

Faculty members also address the teacher/student relationship and dynamics in the classroom that shift as a result of heightened consciousness (Darder et al., 2008). A SF State faculty member described her role as a more than simply a bearer of knowledge. She wants to make sure her students are comfortable in her classroom, as she believe that it will help support their ability to learn. Another faculty member talked about how the 
setup of the classroom also influences the amount of hope her students feel when they leave her course.

I'm a facilitator more than I'm a teacher. And I facilitate learning. I facilitate sharing. And through sharing, you learn. And I think as a teacher, you have power in the classroom. And how you use that power is what matters. So using that power to make sure everybody in the classroom feels good. Everybody in the classroom wants to be there.

A CCSF faculty member agreed and has her own take on dynamics created in the classroom. She described her ongoing struggle to balance authority and collegiality with her students.

I think that especially in a class that's linked to public health and social justice, when you get into the social justice aspect of it and you're looking at inequities, it's vital to look at issues of oppression. I think that one of the driving forces of having a student-centered classroom is you eliminate or you attempt to eliminate any sort of dynamic that would be created within the classroom. So in that way, I think that I'm addressing that taking very careful steps to create gentle balance between authority and collegiality with the students. Because I think both are very necessary. But I don't want it to be a dictatorship. I want it to be a democracy, kind of.

The FLC works with faculty to examine why they are making particular decisions in the classroom. For the faculty member quoted above, there would be a discussion with other members to help her see what others are doing. How do they maintain this balance of authority and collegiality? The group spent time exploring bell hooks' book Teaching to Transgress where they explored their classroom management techniques and tried to articulate the purpose behind those choices. The discussion also led to making sure that students felt hopeful when walking out of our courses. We emphasized an approach that did not simply approach issues of health disparities that we gave them; they were given 
the opportunity to vision a more just society.

Project South talks about critical pedagogy using a lens that goes beyond simply discussing the issues. The organization characterizes a teacher's responsibility using a framework of consciousness, visioning and strategy (Katz-Fishman, 2007). The faculty talk in the FLC meetings, about how it is easy to get caught up in the consciousnessraising stage, but how important the strategy, or action phase actually is. A CCSF faculty member talked about how critical thinking and hope have become much more prevalent in her thinking and her conversations to students after being a part of the FLC.

We are going to analyze problems and we are going to analyze them differently than you know maybe your textbook is or your media will but we are going to analyze them critically. It may become depressing because they seem like intractable problems. We have to look at those problems but I don't want you to be depressed because I want you to see how change is possible and it only is going to come through you. So even in critical thinking classes where you are trying to encourage debate and argument I tell them all the time; there is a goal here. It's to use your analytic abilities to look for alternatives and answers.

A SF State faculty member reiterates this point, by talking about how difficult it can be to ensure there is hope in each lesson.

How do we do that in everyday in a lesson plan? It's a challenge. If you're going to teach oppression and privilege, you better be ready for that challenge and you better take that challenge on. It's unfair to just build awareness and then move on. Then you might as well not. You know like you need to build that awareness and it has to be an empowering asset-based approach. It has to focus on the society and the system as a whole. You can't do it without doing that, tying it
back to the system.

Faculty describe a feeling that they are responsible for instilling hope in their students, similarly to the consciousness, visioning, strategy framework mentioned above 
(Katz-Fishman, 2007). A SF State faculty member echoes this sentiment,

I think that was a really profound shift to my teaching because everything else, it's like I experiment all the time. I am holding myself accountable to always, every time there's a critique of communities in the material, to always offer a place where students feel like they can go for help. Every time you interact with students, like when there's a critique, to also include something hopeful.

Faculty members explore the need for the curriculum to be empowering for their students. Several interviews expressed that simply describing the disparities that marginalized communities' encounter, leaves students hopeless and without tools to create change. This structure around empowering students comes from the FLC mission statement and is reiterated as curriculum that is simultaneously academically rigorous and hopeful, joyful, kind and visionary to allow a community that has conscious to form in the classroom (Bigelow, 2004).

Metro FLC participants heightened their awareness of both making curriculum more relevant to students' daily lives, while simultaneously expressing that change is possible. This dichotomy proved to be challenging for faculty, yet they talked deeply about how the community created in the FLC was a support structure so they wouldn't have to figure everything out on their own.

\section{FLC creates community and support structures for faculty}

A number of faculty talked about how the FLC offers them an opportunity to connect with peers to talk about teaching. Faculty appreciated the chance to reduce isolation in a field that can be solitary in nature. While several faculty were excited about the relationship development, others were more cautious, explaining that not all the 
faculty members in the FLC share a vision of why they teach, and/or, share the same view of the students Metro serves. One thing was clear, however; teaching in higher education can be very isolating, and at the very least, the FLC provided a structured chance for people to interact and see each other, especially interdisciplinary and cross campus meetings, in a way they had not been able to in the past.

One SF State faculty member attributes the FLC to her growth and describes how isolating her teaching career has been to this point.

The opportunity to talk about teaching is so rare once you get out of grad school and I just find it incredibly helpful and enlightening on a professional and on a spiritual level to be able to talk about teaching... with other teachers. You know we work in isolation so often and isolation; there is one teacher and all these students. It is important to be able to talk about practices and just think things through and be reflective. I think that that leads to growth short term and long term.

One SF State faculty member, who started teaching in the university as part of Metro, discussed how the FLC has built her confidence, in addition to making sure she felt supported.

I think in terms of teaching, I'm learning or I'm hearing how isolating it could be without a faculty learning community. I don't know how that [teaching without an FLC] feels, which is great. I don't want to feel marginalized and isolated as a teacher. I think like the faculty learning community definitely gave me more courage. It's built my courage. It's built my confidence as a teacher in a lot of ways.

Another SF State faculty member talked about how she felt a shared vision with members of the FLC and the program as a whole. Faculty have different experiences in the FLC, feeling at times that they share a professional commitment to students, and at 
times, explaining the difficulty that comes from working in a community that brings many different types of instructors together.

Being in Metro has exposed me to people who teach different, who think differently about teaching, and who have a vision of what higher education could be. They take early childhood education, which is what I value, and put it in a professional sense. We are saying these people [early childhood educators] need to be professionals and in our society in order to be considered a professional you need a degree. How do we help them get a degree?

A SF State faculty member talks about how important her relationships with faculty are and how it helps with making her more confident. These relationships translate to easier working relationships with one another, especially as faculty members move toward infusing their curriculum to better support student learning.

I just really like the people. Our math instructors and the critical thinking faculty were a really good mix of people. I think that we came away from the group caring about one another and caring about what we did. I think that the faculty learning community really helps with self-esteem that we don't get, particularly for those of us that are adjunct faculty.

Faculty members love having the opportunity to work closely with other teachers to develop and infuse their courses with socially relevant content. Content in Metro classes includes skill development and social justice related issues. For example, a student may learn in their health education class, how to write a policy brief on the amount of money spent on education versus prisons in the United States. In their corresponding math class, they will learn how to create charts and graphs and be expected to use those skills in their health education class. The FLC is a space for faculty to have these types of conversations about where they can overlap. The faculty take time 
in their meetings to talk to each other about what is happening in their classroom and work with their counterparts to support student learning. One CCSF faculty member talked about her partnership with a fellow instructor.

It's been really fun to work with another teacher in developing [the curriculum], which is something we don't get to do often. I really like being in a learning community with the English teacher and that that relationship is good both interpersonally and academically; it's working. The material, well, it's why I came to teaching. I get to talk about social justice all day long.

This faculty member's English counterpart described the collaboration with regards to her students, in a similar way. She says that she was "ecstatic to hear them making connections between their courses, connections students outside of their cohort may not experience as explicitly. Our learning community was successfully stitching Health and English, seamlessly."

Some faculty members talked about struggles connecting with other members of the FLC. One CCSF faculty member described it as feeling out of place and needing more targeted social activities to get to know one another better. Another faculty member talked about feeling a sense of camaraderie with some faculty, but not all.

I really like some of the faculty as people. They really know their content. But in terms of social justice, I don't get excited about stuff that we talk about because I don't feel like there's any common understanding. I don't feel a certain mutuality of exchange of ideas. I think if the other people and I were more on the same page it definitely would but I don't feel like I'm coming to my group, you know I don't feel like this is my support group

A SF State faculty member reiterated the sentiment of connecting with some colleagues, but not all. 
You know that is a key thing. I would only consider co-teaching, or doing a joint project with a few of you in the FLC. And that's not just because I like you guys personally. I do, but it's because it's that you know what you are doing and you have street cred [ibility] too. There is something to that as well with our students.

One faculty member from SF State said, that even though she feels somehow

challenged and sometimes frustrated by the FLC group as a whole, she says,

So I decided to stay and it has become very important. It has become a group of people that slowly because we only meet once a month, get to know each other even if it's just through academia. Slowly, you pick up bits of people's lives you get to relax, you get to have conversations that are important and it inspires me.

These struggles that faculty describe in feeling comfortable with their peers in the FLC echoes the earlier finding that the community is a place of support and a place of struggle. There is a way that the FLC could do more to build a strong vision and come back to the co-developed mission statement described in chapter 1. Regardless of how faculty members felt about their relationships with FLC members all faculty mentioned that they saw the inherent value of having a FLC. They preferred to struggle through with the members they had, rather than go back to teaching in isolation. Faculty members talked about how the opportunity to learn and share teaching techniques was something they did not receive elsewhere. There was a clear acknowledgement that shifting teaching is not an easy process, and having a group of committed colleagues to learn from made a meaningful impact by giving faculty confidence to change and impetus to make things better. One CCSF faculty member expressed this by saying "I think some of the richest conversations I had about teaching came out of these, the professional development that we've had through the faculty learning community." 
Where the FLC Falls Short: Areas of Improvement

Faculty who participated in the FLC began some important conversations, and improved their feeling of security when interacting with students in the classroom. It gave faculty a window into their own identities and experiences, while giving them space and time in community to explore things that required deeper reflection. In order to continue to grow, however, the structure and content of the FLC needs to shift and change in the same way we ask our faculty participants to transform. There needs to be a more targeted focus on the actual changes made to faculty identity as well as teaching practices.

A CCSF faculty member felt that "What is missing in the faculty learning community is that we never really got the social justice stuff down and like as a solid foundation." She went on to say, "There are definite things that we don't know as people not trained in teaching and it would just be helpful to get more grounded in these things." A SF State faculty member echoed these sentiments by focusing specifically on the type of faculty recruited to teach in the program.

I think it's really important that we have people who are equipped, who aren't just down, who aren't just cool with the program. I guess we want to look for people who are talented teachers; who are committed not just in theory but [really] committed. Their work has a little bit of a resume around the stuff you know, around teaching on these issues. Maybe even working outside in the community in social justice settings. I think those are some of the characteristics that I want to see. First strong teaching skills and then secondarily but very importantly, like a strong kind of commitment to those social justice [issues] in and outside of campus.

Several faculty members talked about how while the social justice aspect was there, it was not often made explicit. Faculty felt also unprepared and vulnerable with 
their peers in transforming their teaching practice into something that operationalized their social justice ideals. Participants asked for more time to struggle together; with content, philosophy, pedagogy and privilege. A CCSF faculty member said that she wants more sharing among colleagues and deeper conversation around power and privilege integrated into the FLC meetings. However, she understands why at times things don't get deep enough, as faculty are tired and overworked by the time they get to the meetings.

I would have more faculty sharing. More focus on pedagogy, more focus on really fruitful and rich conversation around their privilege, etc. I just think about like the faculty who are teaching five classes and they were like get to that meeting and that's when the first second they have to think about what we were about to talk about.

A SF State faculty member talked about the importance of trust in allowing

people to feel confortable going to a deeper place in their conversation.

A lot of those conversations are difficult in Metro we have started and hopefully we will finish and take it to the next level. But also I think it's good to have a solid community that you know to take it to the next level because you are going to come across things that are said that people need to feel comfortable with another in order to hear and not take offensively. Not because they are going to be said offensively or meanly but because the language is charged. The implications, the assumptions are all under there and nobody actually talks about them. I think we do need to challenge ourselves as to "Why am I doing this, why am I thinking this, why do I say this? Are we all really on the same page?"

Several faculty talked about there was an important need for more complex and thoughtful discussion of critical pedagogy threaded throughout the FLC. It was simply not enough to brush the surface; faculty felt it was an integral component of reflecting as a community and wanted much more than they were getting. A CCSF faculty member 
talked about the urgency for faculty to engage in these conversations and to shift their teaching practices toward more socially relevant curriculum in a class that employs critical pedagogy as a framework. She mentions that "People are drawn to a political discussion of you know of the real questions and the real kind of suffering. People from the bottom of the heap are studying for their lives. No joke." Another CCSF faculty member goes on to say that the group of faculty needs to be more willing to have the tough conversations. She says, "The conversations are different when different people are in the room, when there are different levels of power and investment in the room. That's hard I think. And even just the whole power dynamics in our group is challenging."

A SF State faculty member talked about the urgency to transform in the context of the student populations in our classrooms.

I think the way people develop is based on oppression and privilege. I think student development is based on that. I think we often ignore 18, 19, 20 years of life lived experiences. Critical pedagogy, I believe, we need to definitely bring it up in the surface, definitely build awareness of it, definitely acknowledge it and name it, analyze it but then also talk about who to deconstruct it. How do we break it apart? How do we change on a bigger level? In that process, you know, as teachers we should be promoting students to have higher expectations for themselves, for their skills and for their futures.

It is clear from the conversations with faculty, that this process of discovering identities as instructors, integrating deeper analysis of power and privilege and consistently working to make content relevant for students is an ongoing and sometimes difficult one. Faculty described this process, though, as one they cannot imagine going through alone, once they were exposed to the FLC. 


\section{Need a community for true self-reflection}

Faculty members talked about the importance of self-reflection in improving their teaching practice. Some faculty engaged in reflection prior to joining the FLC, and others found the FLC to be helpful in giving them techniques to look inside themselves. Many faculty did feel that being a part of the FLC was key in allowing them to go deeper in their self-discovery as instructors. Community, they said, was important in shining a light on their identities as instructors and in giving them space to talk about things they struggle with. A CCSF faculty member discussed her experience,

When you're in that learning community, the faculty learning community environment, it sort of automatically forces you to think about why you're doing what you're doing, especially how ours was set up. So I think definitely being in that environment with other faculty, even if it wasn't explicit in the conversation, that it made me think and self reflect on why am I doing, what kind of outcomes are we striving for and not so much how we get there but also why we wanted to get there.

Another CCSF faculty member agreed and explained the value of reflection in a

FLC.

Honestly, I don't think that you can really [reflect] it without being in a faculty learning community or having colleagues that you can talk to. I don't think that you can truly evaluate yourself. It would be like giving yourself therapy instead of going to like psychologist you know. I think it's good to self reflect. I had my students self reflect; metacognitive activities are really important in my classroom but it's not enough. We're always curious about what people think about us and how we're being perceived. And unless we ask and seem really kind of creepy we'll never know.

One SF State faculty member talked about the quality of the relationships with her colleagues being a key component to deep self-reflection. Sharing a vision and beliefs 
about students proved important in giving comfort to be vulnerable and open.

To be in a community? That's an interesting question. It really depends what community. If it's a community of people who are all self-reflecting and our missions and our goals and our values are the same or our perspective of teachings are the same, I would love that. I would only want to do it in a community. But that doesn't happen all the time.

A cornerstone to the reflective process seems to include a component discussed as a part of critical pedagogy. Reflection needs to occur within a context, and serve to deepen understanding of structures of inequality and identity within those parameters. A SF State faculty described the purpose of the FLC for her being steeped in building our own knowledge as instructors of the populations we work with. She says, "it's like building our knowledge just about society and about the world and how it might be to be 18 years old and having to work a full-time job to be able to go to school. It's about pedagogy and about our own self-reflection process, critical self-reflection process." I echo these feelings in my own words below.

If you don't really understand or not in tune with what's going on for you personally, you'll never going to be able to grow. That said I'm a product of my environment. I'm a product of my identity and I'm limited. I have blind spots. So I don't think I could really truly come to a different place without having conversations with others, without bringing community into my world of reflection. I feel like having a space where teachers get to talk about what's going on in their classrooms, get to be vulnerable, get to say, "Oh my god, I did this last time and it totally fell flat. What can we do? How can you help me fix this?" It's a space where we get to just question our own motives and desires in the classroom. Why do we choose to do the things that we do? I feel like community is vital for that. I don't think I could really go as deep as I would need to by myself. 
How the FLC Influences Teaching Practice

The goals of the Metro FLC include a deep examination of self and philosophy around teaching. However, the ultimate outcome we hope to see from faculty is transformation in their teaching practice. The participants in this study describe four major ways in which their teaching began to transform as a result of their participation in the FLC. They reported being better able to see the humanity in their students, thinking more deeply about shifts in power and control in the classroom, spent more time on making curriculum relevant and increased the amount of self-reflection on their teaching.

Faculty acknowledge and make more visible the humanity in their students

A few faculty mentioned that one of the impacts of the FLC was that it made them see the humanity in their students more. A SF State faculty member states this by saying, "I think it helped me to be a little bit more comfortable with transparency in the classroom; it helped to allow myself to be more human in the classroom and encourage me as a teacher to look for that same humanness in my students."

A CCSF faculty member further discusses the humanity in her students and talked about understanding that her students face different pressures than she did when she was in school. She talked about her expectations for her students,

You [student] know I shouldn't have to give you this over and over again. You should be coming to school and you should be paying attention. I'm surprised at the number of students that have children and are trying to go to school and I'm thinking, "How on earth do you do homework with a child at home right?" I'm sort of double-checking myself and thinking to myself, "Wait a second. You know he's saying his Mom's sick and you know he can't come, what do you expect him to do?" 
A SF State faculty member described a similar understanding in the following way. He talked about his understanding of his students as individuals.

I learned that in some ways I was not completely in touch with the students' true skill levels (e.g., ability to do research, how to read a textbook, how to apply abstract concepts, how to take an exam, etc.). I learned to be more in touch with the daily social realities of the students (e.g., working multiple jobs, transportation issues, etc.). I also learned that their motivations and priorities are different than mine. I learned to be humble and to inquire more about the students' own biographies.

The exploration of critical pedagogy and hearing from faculty members that know their students well, caused several faculty to see their students in a more favorable light. They took the time to learn student's names, hear more about what was going on with their lives outside of the classroom and made a more concerted effort to check in with their students individually. These principles of relationship building with students were discussed explicitly in the FLC and are questions we continue to struggle with in our meetings.

Power dynamics shift toward a more student-centered approach to teaching

Faculty members expressed the importance of creating collaboration between themselves and their students in the classroom. While there is clear power differential as instructors evaluate their students, faculty talked about how there are several tensions that play out during the course of a semester; authority of instructor versus collegial atmosphere, rigor of content versus (or sometimes, in addition to) support and retention of students in the classroom. A few faculty members spoke of the importance of hearing 
the student voice, and recognizing that students have a wealth of experience and knowledge they already bring when they enter formalized school settings.

Faculty members talked about sharing the space in the classroom with their students. Given the variety of ages in the Metro program, one CCSF faculty member noted,

I have had to create ways of being in my classroom that do challenge the way adults teach adults that do give students more power, more responsibility for reading their own material, more responsibility for their writing, responsibility towards one another. They see my role as different; that I'm not that person filling their head with information.

A SF State faculty member talked about how teaching as a collaborative effort can leave her vulnerable and shift power dynamics away from the instructor as sole bearer of knowledge. Another SF State faculty member described her role as more of a facilitator in the classroom. She said that faculty power should be used to validate the students in the classroom and create an atmosphere that promotes learning at a deep level.

I want it to be a conversation. I want it to be in collaboration and in order to do that I have to extend myself, have to get myself in vulnerable positions. I have to change up how I teach and I have to accept a lot of what comes back to me from the students. I can't ask them for their opinion and they say, "No, I disagree with you. We are not going to do that."

The conversations in the FLC that focus on the collaboration between students and instructors in the classroom appears to be important, and yet, faculty members discuss how maintaining the balance required to be an authority, but trusting in student expertise as a difficult one. In addition, faculty members talked about how reflection back into their own practice in the FLC was important and pushing to challenge pre-existing 
power dynamics made them vulnerable and ultimately, more excited about teaching.

\section{Faculty struggle to make content more relevant for their students}

One of the goals of the Metro Academies project is to develop and teach rigorous and relevant curriculum that has an impact on students' lives. Socially relevant curriculum is a cornerstone of critical pedagogy, and, as argued by Nieto (2003) engage students in thinking about how issues such as poverty, racism and war affect culturally diverse groups "and what students can do to change them" (p.316-317). Another SF State faculty member talked about knowing her students makes it easier for her to infuse curriculum that they care about.

The benefit of being a coordinator is that you already know the students when they come in. You know whom you're going to be dealing with. You know who where high schools they came from. You know what neighborhoods they lived in. So you could tell by just looking at addresses that half of your students are from Bay View. You better be ready to talk about asthma rates in Bay View.

A CCSF faculty member talked about the role the FLC played in getting her classes more focused on real world content. Some of the presentations she particularly focused on in the FLC were directly relevant to how to infuse and teach health content from a social justice perspective. For example, during one training session, we asked faculty to consider why rates of tuberculosis dropped during a particular era in history and asked them to think about the factors that might have caused this drop. While the content of tuberculosis was specific to the health faculty, it gave all instructors a critical lens and a way to talk about data that encouraged students to assess the larger context when describing health disparities. One faculty member describes her experience in 
cutting down some content in her class to get down to the most important points. She says,

It's really humbling and it's a good thing for me to be you know in a situation where I don't know a lot about the subject. What's changed for me is mostly content. I think that a lot of the presentations in the learning community are really helpful reminders. I think everything help shaped and trimmed down the focus of my classes. What I can actually take away and use I think came mostly in content that actually matters.

A CCSF faculty member described what it's like to have her students engage in content that is current and requires them to critically think and argue.

Where students debate on the social determinants of health is also exciting. It's genetics, its behaviors lifestyle, its lack of access to care, its quality of care, its social class but it's disguised as race, you know. Having them each actually look at the material and say well this evidence supports this and this is what debunks this, I feel like that's something my brain does all the time. To see it happen for students is awesome.

The power of connecting content to the real world is a critical pedagogy principle, as knowledge is socially constructed and can't be divorced from the context in which it is created. This struggle for faculty, while difficult, was an important and continues to be something that individual faculty members want to work on in the FLC.

Faculty self-reflect and value having a community to reflect with

As discussed in an early section, faculty identity affects many different aspects of how an instructor teaches. The Metro FLC gave faculty time and space to really reflect on their decisions and forced them to think deeply about why they made those decisions.

A faculty member at SF State talked about how his identity and participation in the FLC changed his awareness of his students. 
Actually, being a part of the faculty learning community made me aware that I was coming from a very privileged position in a way and also in other ways that I'm very out of touch with what is happening with students at this time. I have to remind myself that I need to be explicit about how the things I teach apply to them. How are they relevant to them?

Faculty members employ critical pedagogy by looking at the assumptions they make about students. A CCSF faculty member said that being part of Metro has, "made me question a lot about the values that I've held for so long in a very competitive - I don't assume everybody's had the same kind of education I have but I grew up in a very competitive academically competitive environment." Faculty also see self-reflection as an important part of embodying social justice principles such as authenticity, flexibility and openness to change. A SF State faculty member described her perspective,

You know and I also honestly believe in the reflective work that we do; journal writing, thinking about our teaching and how we can be better teachers, in what ways can we scaffold the lessons, engage in active learning. How do we make curriculum writing intensive and how do we incorporate low-stakes writing? How do we facilitate conversations that allow students to express themselves in a freer way? All of those ways are ways in which we contribute to social justice I think.

Being explicit about what faculty expect from their students comes from a great deal of internal reflection and thought. One SF State faculty member explained her philosophy in the following way,

I think this may sound really cliché but I think I'm guided definitely by love and by hope of knowing that the folks that are in the classroom really are next generations of leaders. That needs to be brought up; that needs to be explicit in the classroom. It needs to be really explicit in the classroom. I think when you go to a yoga class or when you go to a computer class it's so explicit what they expect from you. So why doesn't that happen in everyday classrooms?

Instructors that teach college students must undergo rigorous self-reflection about 
philosophy, methodology and effectiveness if we have any hopes of improving our teaching practice (Bulger, Sean, Mohr, \& Walls, 2002). Many of us do this in isolation, but in the next section, faculty feel that they can go further when they have a community around them to reflect with.

\section{Continuing the Struggle: Moving Forward in Community}

Faculty come into the Metro FLC as a result of identity development and personal experiences in their lives that drive them to improve the educational process for lowincome, first-generation students at SF State and CCSF. They engage in a struggle; $a$ beautiful struggle to overcome fears of being unprepared to teach and judgment that is both internalized and external from colleagues. They lean into the FLC to help address these fears by giving them skills and tools they can use in the classroom. They also value the space to be in community, to reflect on power dynamics, relevant content and their own personal motivations as instructors.

Yet, there is still consistent struggle with how to teach from social justice ideals. There are questions about how to teach and facilitate in the classroom; how to operationalize understandings of critical pedagogy in an authentic way. Clearly, there needs to be a stronger component of the FLC that allows faculty to take risks both in their conversations with one another and in changing their curriculum to try things (such as group activities) with a place for them to come back and report on what worked and what did not. There needs to be space created for instructors to be vulnerable with one another by discussing issues of race, class, gender, sexual orientation, both as they relate to 
instructor identity, but perhaps more importantly, how they play out in the classroom when they are with students. There is a need from faculty to explore the deeper questions around inequity in education, disparities among community health and how we as faculty members use power and privilege to make decisions. Finally, faculty need to have time to infuse culturally relevant pedagogy in their curriculum and faculty development leaders need to encourage faculty by creating a similar structure for FLC meetings and trainings. In the same way we strive to make content relevant for our students, the FLC needs to engage faculty through its own relevant and challenging curriculum for instructors. It needs to facilitate faculty engagement in the beautiful struggle of what it means to be an educator, and how to be the best educators we can be. 
Chapter Five: Discussion and Recommendations

Overview

To educate as the practice of freedom is a way of teaching that anyone can learn. That learning process comes easiest to those of us who teach who also believe that there is an aspect of our vocation that is sacred; who believe that our work is not merely to share information but to share in the intellectual and spiritual growth of our students. To teach in a manner that respects and cares for the souls of our students is essential if we are to provide the necessary conditions where learning can most deeply and intimately begin (hooks, 1994, p.13)

The purpose of this study was to explore the role the Metro faculty learning community played on improving teaching practice. In order to truly understand why an instructor makes particular decisions, it was necessary to go back and find out who the faculty were and explore their motivations to enter the Metro FLC. As facilitator and leader of the FLC, I felt that learning more about how the FLC was meeting the needs of faculty members or not, could help to shape the future of the community by uncovering information that would not be available through simple paper-and-pencil evaluations at the end of our meetings. I wanted to know how to move toward education as the practice of freedom for our entire faculty; engage instructors in the beautiful struggle that is teaching and learning to teach. In its essence, this study explored how faculty learning communities affected higher education teaching practices. More specifically, it examined what motivates people to teach in an FLC, what struggles they face in striving to be better instructors and how participation in the FLC influences teaching practices and in what ways. 
These in-depth qualitative data collected from faculty participating in the FLC suggest three major findings. Faculty were motivated to become a part of Metro for two reasons; they connected as part of their identity (in the form of cultural and economic upbringing) and they wanted their students to have the same or better experiences than they had in school. Faculty members came to the FLC with a number of fears, many of which stemmed from a lack of formalized training in teaching. They reported feeling unprepared to teach, and feelings of inadequacy as instructors were common. Many also shared that they worried about being judged unfavorably by their colleagues, which lead to a reticence to share their insecurities - to be vulnerable - in the FLC. Moreover, Metro FLC faculty members articulated the challenges of operationalizing some of the principles of social justice education through the lens of critical pedagogy.

The Metro FLC was a place where participating faculty felt they could address their fears through struggling together. They felt that the FLC helped to build important teaching skills and techniques they could use in the classroom on a daily basis. They also appreciated having space and time to engage more deeply with issues of power, privilege, race and class in the FLC. Participation in the FLC did influence teaching practice. It allowed them to see the humanity in their students and gave the opportunity to examine shifting power-dynamics in the classroom. For example, faculty members saw their students' lives outside the classroom as important and this understanding allowed them to be more sensitive to competing deadlines. This gave faculty insight into how to be both flexible to student needs and still hold high expectations of the type of work they turn in. 
It made them more aware of the importance of curriculum that is alive and dynamic for students and helped them to critically reflect on all areas of their teaching practice.

In addition, faculty wanted more exploration of the difficult aspects of their job; talking about race in the classroom, handling situations that were stressful, knowing how to address their own limitations as instructors and continue to grow along the way. Specifically, they needed more support in analyzing how to incorporate culturally relevant pedagogy into their teaching practice.

\section{Interpretation of Findings}

The practice of teaching has the potential to engage instructors in a beautiful struggle. I think as educators we engage in this beautiful struggle on a daily basis, finding meaning and difficulty in a myriad of aspects of the profession. The FLC creates as an important place for educators to feel safe enough to dare to struggle together. Faculty members talked about the joy they feel in the classroom, as well as some of the heartbreak that comes with teaching in a society that needs so much work. The reality that we teach in a fundamentally inequitable education system affects instructors as well as students deeply.

One of the most difficult parts of our jobs as educators is recognizing that as much as we want to, we cannot affect the context of the lives of our students. We want them to be in class, to do the work, to critically think and to be empowered to go out and make change in their communities. It's what is so hard, and what can be so incredible about teaching. We know that our students are already out in the world doing amazing things. Our jobs are to build skills, impart wisdom and sometimes, just get the hell out of the way and listen. It's hard to remember sometimes, but our own humility, who we 
as instructors are in the world, teaches a lesson to students as powerful as any content we deliver.

Faculty members describe the factors that motivated them to teach as part of the Metro program in the next section, which sets up the context for the further findings on identity, fears and influence on teaching practice.

\section{Motivations to teach in Metro}

Members of the Metro FLC came into the program primarily through recommendations from department chairs. This process of selection, vetting and entry in to the Metro FLC, may have made the sample biased toward people with ideals that align (in some ways) with the Metro philosophy. How faculty were recruited to teach in Metro and their desire to change teaching practices may come as a result of being recommended into a program that requires a faculty learning community. Metro offered hope. A CCSF faculty member said it was a place for her to "grow in to the teacher I always thought I should be."

Metro offered hope for faculty and there was little doubt that faculty identity matters. How faculty interpret the meaning of their identity in the classroom differs from individual to individual, but it is clear that faculty see their racial, ethnic identities and cultural and economic upbringing as instrumental in how they view their teaching practice and their students. This understanding of the role identity plays in teaching, however, is clouded by our own biases and has the potential to get in our way as we strive to become better instructors. Not being able to acknowledge both similarities we 
share with our students and distance that exists, can prevent us from being authentic in the classroom and we may miss key opportunities to connect and grow in the same way our students do.

One important aspect of the FLC that needs to shift going forward is addressing the essentialist perspective (seeing faculty that mirror their students according to race or income, for example, as more qualified to teach, than faculty that don't share those characteristics) that comes out when faculty members talk about how their race or economic upbringing plays a role in the classroom. It's a difficult balance. On one hand, making the claim that faculty must be representative of the students they serve is nearly impossible. The complexities of identity are too great to be captured by any single variable (ex. race, class, gender, sexual orientation, etc.). Since these identities are distinct for both students and instructors, and are not additive — they interact with one another to create more complex experiences of school and life and thus cannot be treated as one identity (Collins, 2008; Crenshaw, 1991). There is no reason why FLCs can't support and build phenomenal teachers from all backgrounds and walks of life. On the other hand, faculty members do need to do the internal processing of what their identity development has been in their lives. In doing so, they must work to connect their identities with their philosophies and actions in the classroom. This is essential because there are implications for students when this work does not occur. Faculty must be critical thinkers and critical reflectors about their teaching practice. "A robust inclusive curriculum delivered by an instructor who has not come to terms with her or his 
relationship to identity can be a recipe for disaster" (Alejano-Steele et al., 2011, p.92). In order to embody critical pedagogical principles, faculty need to continuously examine the context in which students are learning, as well as look as the ways in which knowledge is constructed.

In describing a FLC based around "critical conversations," Alejano-Steele (2011) talks about how the most effective FLCs ask their faculty to not only depart radically from their old assumptions about how education is delivered, but also to shift their spirit and philosophy to some extent towards seeing their students as more than just who they are in the classroom. These principles need to be integrated more fully throughout the FLC experience, as the data shows that many faculty members do not often have the time or opportunity to work closely with like-minded colleagues on their teaching practice, specifically.

Many faculty recognized that they wanted to see their students experience the same or better education that they had received themselves. A CCSF faculty member talked about tapping into the notion that many people who have become teachers must have had favorable educational experiences that have shaped their career trajectories in important ways.

So I want a kind of excitement in my classroom and I don't get it that often. That's something I bring from my experience in college, in my experience with learning. I mean, most of us who teach; we didn't hate college, we didn't hate school. If we did we wouldn't teach. We may have hated certain experiences, we may have felt humiliated at certain times but we didn't leave college saying, "Never go back," or else we wouldn't have you know. 
Other faculty members described less than desirable educational experiences, which caused them personal pain, but nonetheless also led them into teaching. These perspectives show a clear understanding of the inequities that exist for students today. The faculty members that wanted a similar experience for students were typically not from disadvantaged backgrounds (based on race/ethnicity or socioeconomic status). Moreover, they typically attended schools where they had small class sizes, personalized attention from faculty members, and - at times - were given real opportunities to engage in the creation of the curriculum in which they participated. The faculty members who wanted better for their students were generally students from disadvantaged backgrounds who described their early educational experiences as racist, unjust, and not adequately challenging.

The assumptions that we make as faculty about one another prove dangerous and have prevented us as a community from digging into questions of identity, race, class, gender and the influence of those characteristics on our interactions with the world. I underestimated the fact that we as a faculty group would collectively need to have to unlearn racism, to understand our assumptions about class and gender and to really examine our own biases of not only our students, but also one another.

In addition, I also made the assumption that each member of the Metro FLC came into teaching with an intense desire and passion to improve our teaching practice. The acknowledgement that faculty come from a variety of places in relation to their level of investment in their teaching practice is an important realization, in developing faculty 
learning community that can meet the needs of all faculty members. Understanding that many instructors come into teaching as part of a career change, or after doing other things in the world, could shape how the FLC develops and comes together. There may be other things that the faculty members have in common, outside of teaching, that play a big role in their classroom and teaching philosophy. Identifying these interests and tapping into the vast expertise that faculty have, could make the community experience richer for all, which is echoed by hooks (1994) in the following quote:

Among educators there has to be acknowledgements that any effort to transform institutions so that they reflect a multicultural standpoint must take into consideration the fears teachers have when asked to shift their paradigms. There must be training sites where teachers have the opportunity to express their concerns while also learning to create ways to approach the multicultural classroom and curriculum. (p. 36)

Fears and struggles of instructors in the FLC

Faculty fears and insecurities created the foundation of the struggle to elevate teaching practice. The narratives of these instructors reflected the deep fears that teachers have about transforming themselves. They do not want to appear awkward or unskilled in front of their students or their colleagues (Shor \& Freire, 1986). Yet, such fears have the ability to both stifle and motivate. Palmer (1997) describes bad teaching as when we allow fear to get the better of us. He writes that fear is actually what gives ignorance its power (Palmer, 1997). On the other end of the spectrum, Shor \& Freire (1986) bring out the humanity in fear, saying that fear is inherent in every human being and that we shouldn't try and suppress it. They question those who don't feel fear in teaching, stating 
that "If your dream was to preserve the status quo, what would you fear then?" (Shor \& Freire, 1986, p. 56). Both perspectives explore the essence of teaching, which includes recognition of the reality fear and the role it can play in affecting teaching practice. . Thus, FLCs must embrace fear and work with faculty to work with their fears, as well as through them, as illustrated in the quote below,

Any classroom that employs a holistic model of learning will also be a place where teachers grow, and are empowered by the process. That empowerment cannot happen if we refuse to be vulnerable while encouraging students to take risks (hooks, 1994, p. 38)

Vulnerabilities expressed by this faculty included their fears of judgment from colleagues and feelings of inadequacy as teachers. We worry we will make mistakes in the classroom and lose control or respect (Shor \& Freire, 1986). Teaching leaves us vulnerable, with our passions exposed, to scrutiny and judgment from our peers and our students (Palmer, 1997). Yet this ability to be vulnerable, to take risks with our students, creates a connection; a bond that allows the students to learn in our classrooms. It allows them to see us as human. In the same way we encourage our students to make mistakes as a natural and useful part of the learning process; we also must be open to confronting our fears, taking risks and sometimes failing. By not opening ourselves up to our students, we let the fear control us. Joining a community of faculty is one way to test the waters together, before we are in front of students. The Metro FLC gave faculty a space to feel fear, name it and do what they could to move past it. 
Faculty members felt that they needed support operationalizing principles that we discussed around critical pedagogy. This area of change in the FLC is perhaps the most important. The literature on FLCs in higher education devotes a great deal of attention to skill building for faculty. It describes techniques such as active learning strategies as areas of growth for faculty members and emphasizes the importance of real exchange and community building. However, there is very little that includes an analysis of power, privilege and societal level factors and their influence on faculty and teaching. There needs to be a more targeted focus on faculty identity as a fluid construct that shifts and an examination of how our own assumptions about one another effect our actions with students. Threads of critical pedagogy must be better integrated throughout the professional development plan for a FLC. Each training session, conversation or speaker should have a focus on addressing critical issues for faculty, which includes conversations of equity, resistance, and power. True faculty learning communities are developed when inquiry and practice collide, when discourse critically examines how knowledge is constructed in the context of social forces and when we are able to be honest about our own fears and limitations as instructors.

\section{FLCs and transforming teaching practice}

In order for faculty to truly transform their teaching practice, they must be willing to engage in the beautiful struggle on an ongoing basis. The FLC gave faculty members a place to work together and explore teaching techniques to which they may have not been previously exposed. This Metro faculty felt that their experiences in the FLC led them to 
see more humanity in their students. They moved from being teacher-centered to focusing on what students would actually learn in their classrooms, first and foremost. The FLC offered them space to share their successes and challenges with their students. One of the most powerful things we do as a faculty is talk together about how we can collectively support student improvement. This exercise gives us the ability to share strategies that work with one another, and troubleshoot problem areas in our own teaching. Being able to see our students holistically - not only as students but also in the broader social contexts of their lives - and work toward creating a relevant curriculum that will engage them, also engages each of us more thoroughly in our craft as teachers.

We ask our students to engage with material in the classroom. As instructors, we need to do the same in the FLC. The content of the FLC must be relevant to faculty members and force them to think and grow in ways they haven't before. Self-refection individually and in community is one way to make this happen, but there is a real need for thoughtful FLC curriculum development. Too often, we engage in faculty development that is a one-shot deal; that is a workshop, training or listening to a guest speaker. For true transformation, FLC meetings and exchanges must happen continuously in response to an ongoing discourse regarding what the faculty experience day to day, and the assistance and support they feel they truly need. At the same time, the activities of the FLC need to be based in a theory and practice feedback loop, where theory informs practice, which again informs theory. The action and reflection loop continue to occur simultaneously, creating a culture of constant improvement. 
Finally, one of the other outcomes of this study is that more research based on principles of CBPR needs to be conducted in higher education institutions. In essence, this study uses CBPR to break down some of the power dynamics that often exist between the researcher and subject. Research and action become intertwined as the purpose of the study becomes about transformation for all involved (participants, researcher, advisory group members) and the outcome applies the results of the research immediately to a concrete situation. If we hope to see improvement in our teaching practice, we need to study it with as much passion as we study other things in our world. Doing it collectively, with an eye toward improving instruction in our entire institution, requires us to engage those that are affected by our teaching in every step of the research process.

\section{Study Limitations}

This study follows a particular group of faculty who are part of a unique program. The program spans two very different institutions and attempts to bring together a common set of objectives that the FLC hopes all instructors will have. While there were many conversations about the community college versus four-year university distinction, this study does not detail the unique barriers instructors face at each institution. The idea of the FLC from its inception was to bring together both sets of instructors, to build a community, and bridge a partnership between Metro at CCSF and Metro at SF State. For this reason, little attention was paid to the specific needs of instructors based on their teaching time base. The push toward collegiality between campuses allowed me to 
overlook the need to build community within institutions as much as I did between them. This has shifted in the FLC within the last semester and will continue to be a part of the plans moving forward.

My professional career in education began as a middle school teacher in $\mathrm{K}-12$; where the notion of professional development is embedded into the teaching day. My experiences of working with middle school teachers for years gave me the false assumption that a similar system would exist in higher education. The lack of this institutional structure in post-secondary education was at first difficult for me to recognize, and I see more clearly now the importance of addressing fears associated with feeling unprepared to teach in FLCs for instructors who begin their teaching careers in community college or university settings.

Finally, this study is largely missing a significant voice: that of the students. Even though students were involved in the research process, the study itself focused on the experiences of faculty; a population that is not studied as often as students, however, student voices are important in gauging the influence of the FLC on their experiences in the classroom. Further research can be done in the form of an impact study. Does the FLC improve outcomes for students? Given the complex nature of the Metro program, this may require a more detailed mixed-methods protocol, but could potentially make the case stronger for why a FLC is not only better for faculty, but better for students as well. 


\section{Implications}

Institutions with an agenda to transform instruction and thus affect student outcomes should look to faculty development as an important first step. FLCs create time and space for faculty to work together - in the beautiful struggle - and ultimately to transcend the primarily individualistic culture in the academy (Petrone, 2004). They also can move institutions toward being focused on learning, not just for students, but also for faculty (Cox, 2004).

\section{Reflection, Community, Action}

Elmore (2004) describes teacher study groups as a powerful way to change teaching practice. He says, "Ambitious teaching should be a professional expectation, not limited as a solely individual trait” (p.28). Facilitating study groups of willing participants requires leadership that is visionary, leads with emotional intelligence and empowers talent across campus and at a variety of levels (Petrone, 2004). These skills are developed through intentional knowledge about new ways to teach, encouragement and support, access to special knowledge and time - time to focus on the requirements of emerging challenges and tasks and time to observe others who are responding and working effectively (Elmore, 2004). This potential for continued organizational change lends itself to authentic, shared leadership that is democratic in nature, and where the talents of each individual are showcased and honored (Elmore, 2004). In addition, the leaders of a FLC understand the importance of developing connections across initiatives and individuals on campus (Eckel et al., 1999). These connections and individual 
strengths can lead to new conversations and a clearer vision and mission for what FLCs should strive toward, and how.

Any FLC that hopes to engage in issues of social justice cannot train and support faculty in the absence of culturally-relevant and critical pedagogy. It is easy to make assumptions about where the faculty stands on important issues; what their expectations are of their students and what relevant curriculum means to them. Making such assumptions about faculty can be dangerous, as it can shape a professional development plan that does not meet the needs of its members. Faculty community leaders need to treat their professional development programs with the same level of thought and care they bring to their classrooms. There needs to be a robust curriculum that clearly promotes faculty growth in the same way that teaching promotes student learning. In short, good teaching requires ongoing professional development.

\section{Recommendations for Action}

I offer two main types of recommendations for action. The first concerns recommendations for practice, where I discuss how the findings of this study can be used to enhance the FLC, both for Metro and for institutions more generally. The second concerns recommendations for policy, where institutions could make larger systematic changes to allow the fluid integration of FLCs into any existing structures or programs promoting faculty development. 


\section{Practice recommendations}

The Metro faculty described a need for "more" in the FLC than what they are currently getting. They talked about feeling supported by the community, were gaining strategies that were useful as instructors, and were thinking deeper about their own identity as it related to their teaching practice. They also described feeling that there was not enough time to talk about issues of social justice, or to really dig deep into how their understanding of critical pedagogy could be implemented individually. One faculty participant talked about wanting the FLC to mirror an amazing class she took as a student. She said,

I would want the faculty learning community to be like the greatest class I ever took. I don't know how to make it that way. I mean there are moments when it's like that. What made something the greatest class I ever took was that I was super into the topic, the instructor was amazing, and the other students in there were amazing. We were doing great things in there.

If our mission in Metro is to have culturally and socially relevant, engaging curriculum for our students, we need to provide the same for our faculty. It is easy to create a faculty development plan that focuses specifically on teaching techniques; it's another thing to thread our values around social justice through everything we do for instructional change. The goal is to help one another as instructors, to transform us as teachers and elevate teaching practice. If that's the case, we need to be exposed to transformative professional development opportunities, which means going to a deeper level.

It is also clear that faculty want to join FLCs to confront an array of fears that 
impact their teaching practice. Within the FLC, the inherent struggles of addressing these fears become shared, which provides important support and guidance for participating faculty. For this reason, there needs to be a more targeted approach to addressing faculty fears. The once per month meetings need to include more faculty sharing - more opportunities to share their concerns, their expertise, and their resources. There also needs to be an understanding given to faculty at the beginning of their work within a FLC that they are engaging in a life-long learning process - as they wish for their students. In the life-long processes of teaching - and learning - we can transcend our individual limitations, biases and assumptions to thrive as teachers and elevate teaching practice. Institutions need to create safe spaces like a FLC, where we can explore our own context, talk through inequity and acknowledge the destructive nature of that inequity and take action, collectively. There needs to be a commitment to continuous engagement in the beautiful struggle and relationships where if members of the community are missing, their absence is felt by all.

\section{Policy recommendations}

On a systems level, one reason that the Metro FLC maintains momentum is that we started small, with a core group of committed faculty members. For those wanting to begin a FLC, it will be important to start with a small planning group at the department level. I don't make the assumption that many faculty currently are working in interdisciplinary teams, so working within a department seems like a practical way to start. The reality is that as the faculty leader of this FLC, I don't hold a great deal of 
authority. I enter the room as a peer and attempt to create an atmosphere of ideas, inspiration, reciprocity and respect for all involved. Faculty members mention that the intentionality of my actions, from the overt organization of the meetings using structured agendas and sticking to commitments of exactly three hour meetings, to the subtle ways in which I interact with the faculty through email and phone calls were appreciated. Faculty mentioned individual connections between them and me, beginning and ending on time, timely follow up, ability to listen to cues and change things up in the moment were all ways in which a strong facilitator leads an FLC. While I am a peer with no supervisory or evaluative role, there is an element of expertise that is afforded to me as facilitator of the FLC.

In addition, the importance of community building cannot be underestimated in beginning to develop a culture of collegiality specifically around teaching practice. There must be a shared commitment to student-centered instruction as this requires some extra work (internally and externally) from each faculty member. In addition to a faculty leader, there needs to be buy-in from department chairs as well as other faculty with power in the department. Ideally, there should also be a partnership set up with the center for teaching and learning on campus (if there is one), to share resources and ideas for faculty development.

At a department level, the ideal scenario is to build in time at every faculty meeting that is devoted to building FLC and discussion of teaching practice. As committed as the Metro faculty members are to their participation in the FLC, asking 
them to put in more time over already tight schedules for development is difficult. If there were time embedded into faculty meetings that already exist on semester calendars, it could shift towards a culture of improvement while building the skills of faculty in each department. At an institutional level, a few days of faculty development a year are simply not enough. There needs to be a commitment on an ongoing basis to work with all faculty and linking scholarship to teaching at the 4-year university could be one way to ensure continuous improvement. The leader of instructional change should ideally be the department chair, but faculty leaders can also contribute to the culture of transformation and explore credit for their participation in a planning team as part of department service. There are a myriad of resources at any institution's disposal to help implement FLCs broadly across campuses; it's a matter of allocating them to instructional improvement (Cox, 2004; Grubb, 1999).

\section{Dissemination plans}

These findings will first be disseminated to the faculty participants. The advisory group met on April 3, 2012, for their final meeting and discussed the best ways to share the findings from this study. Both faculty and student advisory group members agreed that these findings needed to go back to the community they came from, namely the participants in the Metro FLC. They suggested a conversation at an upcoming FLC meeting, where one student, a faculty representative and I could talk about the findings and discuss the feasibility of some of the recommendations presented in this chapter. The group also mentioned that the findings from this study could be propelled into another 
collaborative process, where students, faculty, administrators in the Metro program could come together to write chapters in a book that details some of the approaches used to reform higher education. Finally, the students felt that they wanted to see the findings used to help instructors in other departments, not just the faculty that taught in Metro, and suggested that I spend time presenting and talking to chairs at both institutions about how to create FLCs with their own faculty members.

\section{Recommendations for further study}

This study profiled the faculty learning community of a cross-campus program between a two and four-year institution. As mentioned previously, there are unique features of the Metro Academies at CCSF and the Metro at SF State. The two institutions are very different, and these contrasts need to be documented. One SF State faculty member commented on these distinctions and the importance of being able to learn from community college faculty, as part of his interview. He said,

I find that the instructors at City College are much more radical than we are. In that sense, I find I can learn more from them in some ways. Not that I cannot learn from [SF State faculty], but differently. We're [SF State faculty] very domesticated in a lot of ways. In looking at some of the materials that our folks at the City College are using in their classrooms, I'm thinking that is pretty radical. At the beginning, I really didn't expect that.

The FLC builds capacity in instructors between colleges, which has very important benefits to students. Many students that transfer from CCSF to SF State end up in either Health Education or Child and Adolescent Development, keeping them connected to the faculty from the Metro programs when they transfer over. Faculty 
members also report that their participation in the FLC translates to sharing of what they discussed in the FLC with colleagues in their home departments. In addition, as mentioned previously, a study that included student voices as part of the findings, would add depth to the faculty perspective of the influence of the learning community.

\section{Reflections on the research process}

Since I was 16 years old, I have been intimately involved with many different aspects of the educational process. I have worked as a mentor, a tutor, a middle school teacher and department chair, and now I work both as an administrator and a teacher in a university setting. In every facet, I have witnessed a genuine and pervasive need for anyone who interacts with students to be involved in what I have characterized as struggles that must be shared: the struggle against inequity, the struggle for voice and representation, the beautiful struggle to be the best educator humanly possible. My role as the facilitator of the Metro FLC affords me a unique perspective on faculty participants in this study, one that allows me to see them as more than simply research subjects. They are people with whom I have worked closely, and together we continue our struggles to become better teachers. While this may be seen as a bias, the entire point of this study was to engage in a collaborative inquiry that aims to strengthen the Metro FLC and inform the development of other FLCs (Jenlink \& Jenlink, 2008). The faculty who took part in this research knows that their narratives will influence the Metro FLC as it moves forward, and in particular that they will help me to strengthen my work as the group's facilitator. The following section gives a glimpse into how the faculty viewed my role in 
the community.

\section{Reflections on the researcher}

This section comes from the data gathered from one-on-one interviews that speaks directly to my role in the FLC. As with many things in higher education, in order for a new initiative (the Metro FLC) to take shape, it needs to be someone's job to spend time thinking about it and crafting a professional development plan. Faculty talked about how there needed to be a facilitator to run the FLC meetings, put together agendas, evaluate the meetings and check in with faculty individually. That said, there were limitations to my facilitation and faculty, in some of the comments below, expressed these limitations. Two SF State faculty members describe the need for a particular skill set to be an effective FLC facilitator.

You are in a different role in the learning community though because you are diplomatic, you have to be. I mean to get people in the room, to get people to buyin you know, if you are going to be abrasive people are going to push back on that and it's about personality not about content not about anything else. So I think the way your personality is it's nicely suited to handle all these crazy different people including myself.

I think in order to lead a faculty learning community it takes a very unique skill set and I think we learned that. I think we really need to be clear on what are the key characteristics and traits that somebody leading needs to have. Because, I think if you have the wrong person in place to lead those meetings and to facilitate those meetings and plan, then people could have a very different experience in those faculty learning communities.

A CCSF faculty member talked about holding the role of facilitator more fluidly.

She discusses exploring a shared facilitation model, rather than the model we currently use, where I am solely responsible for creating agendas and developing the training 
modules.

You don't have to do it all, you know you can have people take turn and facilitate those conversations and even just you know like even if we did a reader or something like that, it doesn't have to be you leading it all the time. You can make other people, force them to take the lead on or they could pick a part, you know we could take turns and pick a theorist from this list that we have or our own.

\section{Reflections of the researcher}

As the facilitator, and somewhat informal leader of this community of faculty, there are several things I would like to see shift. Below are some of my own reflections about taking on the role of facilitator of a diverse group of faculty from two institutions.

Being a facilitator, I have straddled the line between learner, peer and coach. In someway, the someway, the faculty leaning community is a classroom right? It is an opportunity for us to really explore some of these super difficult issues around race, class, identity and values in the classroom. I am realizing that in the last three years I pushed my students a hell of a lot harder than I push the faculty and what is that about?

A SF State faculty member who shares the role of administrator and instructor in Metro talks about the benefits of being both. I agree with her assessment, and feel that if I didn't have the link to the classroom, that my own credibility would come into question. At the same time, I am privileged to have space and time in my daily job to put energy into thinking about faculty development that my peers who teach five classes don't have.

A CCSF faculty member talks about being disappointed by the Metro FLC. Her concerns are ones that we are attempting to address, but will be fleshed out in more detail in the recommendations section. Prioritizing faculty community and commitment to transformation is one of the major issues that she talks about below. 
I think it's been hard on many levels. I think getting the faculty to understand what Metro is has been really hard and spending time on the community has been awkward. I think having people come and go has been hard both among us and among the faculty. Maybe those are things we just needed to plan for and like upfront plan for since of course that's going to happen. That's been hard. I feel like all of us our participation has waxed and waned. I think that when the leadership isn't even showing up, what does that say. That's not good.

There is also a systemic struggle about building community that needs to be addressed. In the quote below, I spoke about my former life as a middle school teacher, and the differences in faculty development between the educational systems.

Because this [building faculty community] is something I actually really care about and have wanted, you know I've done faculty development with I was K-12 teacher. And it was a very different [animal]. I saw my faculty every week for an hour and a half. It was just different. And they have come from teacher credentialing programs. So they have that kind of basis you know. It's like starting from complete scratch and the same thing and how do I, looking at my own limitations as a facilitator as well, really make this a transformative process? And like how do I bring folks in that have expertise that I don't to kind of build out a more robust program, which I haven't done Conclusion in the past. I definitely don't think it's done. We have a long way to go.

"In the learning community, I want to be challenged. Not bored, and not holding someone's hand through the difficult stuff. Put us in a setting where we can be challenged" (SF State faculty member, personal communication, October 2012). FLCs can create an important space for faculty members to explore their identities, honor their values in education, and struggle with important issues that will ultimately make them better teachers. A robust FLC will treat the professional development of faculty with the same care that we treat our courses. It will contain a rigorous and challenging curriculum that pushes faculty members to move beyond their fears, beyond their comfort and into 
difficult spaces. It needs to include values and principles of social justice and encourage faculty to think deep and potentially change their practice to reflect critical pedagogical principles. It can work within existing institutional structures; it will require leadership at the instructor and department levels and could potentially shift the culture towards a more integrated focus on instruction.

Participation in a FLC can also reignite a passion for teaching that is often lost due to institutional constraints of working in higher education such as focus on research or service to the institution. Being a part of the FLC allowed faculty members to feel a sense of pride in being teachers. In the same way faculty members describe feeling energized and invigorated when her students transform, the same feeling can happen at an institutional level when we see faculty make a transformation that positively impacts their students. It moves our discussion away from a purely budget focused approach to faculty development, toward a new way. The way of community support, accountability to one another and to students, relationships and an underlying love for one another, our students and our profession. It is a privilege to be engaged in a beautiful struggle. Lots of faculty, across the United States, are not engaged in the struggle and need to be invited in. Creation and maintenance of a FLC is a great way to invite them in to allow them to face their fears and not hide from the struggle. It's a place for faculty to struggle together; to struggle against inequity, to struggle for voice and representation, to engage in the beautiful struggle to be the best educator humanly possible. 


\section{References}

Alejano-Steele, A., Hamington, M., MacDonald, L., Potter, M., Schafer, S., Sgoutas, A., \& Tull, T. (2011). From difficult dialogues to critical conversations:

Intersectionality in our teaching and professional lives. New Directions for Teaching and Learning, 2011(125), 91-100. doi:10.1002/tl.436

Austin, A. E. (2000). Heeding New Voices: Academic Careers For A New Generation. Forum on Faculty Roles \& Rewards, American Association for Higher Education. Bailey, T. R., \& Alfonso, M. (2005). Paths to persistence: An analysis of research on program effectiveness at community colleges. Lumina Foundation for Education New Agenda Series, 6(1).

Bain, K. (2004). What the Best College Teachers Do. Harvard University Press.

Bartolome, L. I. (2004). Critical Pedagogy and Teacher Education: Radicalizing Prospective Teachers. Teacher Education Quarterly, 31(1), 97-122.

Bernacchio, C., Ross, F., Washburn, K. R., Whitney, J., \& Wood, D. R. (2007). Faculty Collaboration to Improve Equity, Access, and Inclusion in Higher Education. Equity \& Excellence in Education, 40(1), 56-66.

doi:10.1080/10665680601066511

Bigelow, B. (2004). Rethinking Our Classrooms: Teaching for Equity and Justice. Volume 2. Revised Edition. Rethinking Schools, Ltd. 1001 East Keefe Avenue, 
Milwaukee, WI 53212. Retrieved from

http://www.eric.ed.gov/ERICWebPortal/detail?accno=ED521821.

Bok, D. (2005). Our Underachieving Colleges: A Candid Look at How Much Students Learn and Why They Should Be Learning More (1st ed.). Princeton University Press.

Bowen, W. G., Chingos, M. M., \& McPherson, M. S. (2009). Crossing the Finish Line: Completing College at America's Public Universities (First Edition first Printing.). Princeton University Press.

Brock, T. (2010). Community College as a Pathway to Higher Education and Earnings. THE WHITE HOUSE SUMMIT ON COMMUNITY COLLEGES, 41.

Bulger, Sean, Mohr, D., \& Walls, R. (2002). Stack the Deck in Favor of Your Students by Using the Four Aces of Effective Teaching. Journal of Effective Teaching, 5. Retrieved from http://uncw.edu/cte/et/articles/bulger/

Carr, W., \& Kemmis, S. (1986). Becoming Critical: Education Knowledge and Action Research (1st ed.). Routledge.

Chen, X., \& Carroll, C. D. (2005). First generation students in postsecondary education: A look at their college transcripts (NCES 2005-171). US Department of Education. National Center for Education Statistics. Washington, DC: US Government Printing Office.

Chickering, A. W., Gamson, Z. F., \& Poulsen, S. J. (1987). Seven Principles for Good Practice in Undergraduate Education. Johnson Foundation. 
Collins, P. H. (2008). Black Feminist Thought: Knowledge, Consciousness, and the Politics of Empowerment (1st ed.). Routledge.

Cox, M. D. (2004). Introduction to faculty learning communities. New directions for teaching and learning, 2004(97), 5-23.

Crenshaw, K. (1991). Mapping the Margins: Intersectionality, Identity Politics, and Violence against Women of Color. Stanford Law Review, 43(6), 1241-1299. doi: $10.2307 / 1229039$

Cross, K. P., \& Steadman, M. H. (1996). Classroom Research: Implementing the Scholarship of Teaching (1st ed.). Jossey-Bass.

Darder, A. (1991). Culture and Power in the Classroom: A Critical Foundation for Bicultural Education. Bergin \& Garvey Paperback.

Darder, A., Baltodano, M. P., \& Torres, R. D. (2008). The Critical Pedagogy Reader: Second Edition (2nd ed.). Routledge.

Darling-Hammond, L. (2010). The Flat World and Education: How America's Commitment to Equity Will Determine Our Future. Teachers College Press.

Darling-Hammond, L., \& Sykes, G. (1999). Teaching as the Learning Profession: Handbook of Policy and Practice. Jossey-Bass Education Series. Jossey-Bass Inc., Publishers Retrieved from http://www.eric.ed.gov/ERICWebPortal/detail?accno=ED431368

Denzin, N. K., \& Lincoln, Y. S. (2007). Collecting and Interpreting Qualitative Materials (3rd ed.). Sage Publications, Inc. 
Dewey, J. (1910). How we think. D.C. Heath \& Co.

Dill, D. D. (1990). What teachers need to know: the knowledge, skills, and values essential to good teaching. Jossey-Bass.

Duncan-Andrade, J. (2007). Gangstas, Wankstas, and Ridas: defining, developing, and supporting effective teachers in urban schools. International Journal of Qualitative Studies in Education (QSE), 20(6), 617-638.

doi:10.1080/09518390701630767

Eckel, P., Hill, B., Green, M., \& Mallon, W. (1999). On change: reports from the road: Insights on institutional change (p. 16). Washington, DC: American Council on Education.

Elmore, R. F. (2004). School reform from the inside out: policy, practice, and performance. Harvard Education Press.

Erikson, E. H. (1963). Childhood and Society. New York: W.W. Norton \& Co, Inc.

Finlay, L. (2008). Reflecting on “Reflective practice.” PBPL paper.

Folbre, N. (2010). Saving State U: Fixing Public Higher Education. New Press, The.

Freire, P. (2000). Pedagogy of the Oppressed, 30th Anniversary Edition. (M. B. Ramos, Trans.) (30th Anniversary.). Continuum.

Gallucci, C. (2008). Districtwide instructional reform: Using sociocultural theory to link professional learning to organizational support. American Journal of Education, $114(4), 541-581$. 
Gay, G. (2000). Culturally Responsive Teaching: Theory, Research, and Practice. Teachers College Press.

Giroux, H. (1986). Teacher education and the politics of engagement: The case for democratic schooling. Harvard Educational Review, 56(3), 213.

Glanz, K., Rimer, B. K., \& Lewis, F. M. (Eds.). (2002). Health Behavior and Health Education: Theory, Research, and Practice (3rd ed.). Jossey-Bass.

Glasser, W. (1986). Control Theory in the Classroom (Revised ed.). Harpercollins.

Goode, W. J. (1957). Community Within a Community. American Sociological Review, 22(2), 194-200.

Gramsci, A. (1971). Selections from the Prison Notebooks. (Q. Hoare \& G. N. Smith, Eds.). International Publishers Co.

Grossman, P., Wineburg, S., \& Woolworth, S. (2001). Toward a Theory of Teacher Community.

Grubb, W. N. (1999). Honored But Invisible: An Inside Look at Teaching in Community Colleges (1st ed.). Routledge.

Herr, K. G., \& Anderson, G. L. (2005). The Action Research Dissertation: A Guide for Students and Faculty (1st ed.). Sage Publications, Inc.

hooks, b. (1994). Teaching to Transgress: Education as the Practice of Freedom. Routledge. 
Hutchings, P., Huber, M. T., \& Ciccone, A. (2011). The Scholarship of Teaching and Learning Reconsidered: Institutional Integration and Impact (1st ed.). JosseyBass.

Israel, B. A., Eng, E., Schulz, A. J., Parker, E. A., \& Satcher, D. (2005). Methods in Community-Based Participatory Research for Health (1 st ed.). Jossey-Bass.

Jenlink, P. M., \& Jenlink, K. E. (2008). Creating Democratic Learning Communities: Transformative Work as Spatial Practice. Theory Into Practice, 47(4), 311-317. doi: $10.1080 / 00405840802329300$

Jetton, T. L., Cancienne, M. B., \& Greever, B. (2008). The Evolving Roles of Faculty Learning Communities: A University/High School Literacy Partnership. Theory Into Practice, 47(4), 327-335. doi:10.1080/00405840802329342

Johnsen, H. L., Pacht, M., van Slyck, P., \& Tsao, T. M. (2009). The Messy Teaching Conversation: Toward a Model of Collegial Reflection, Exchange, and Scholarship on Classroom Problems. Teaching English in the Two-Year College, $37(2), 119-136$.

Karpiak, I. (1997). University professors at mid-life: Being a part of...but feeling apart. To Improve the Academy, 16, 21-40.

Katz-Fishman, R. B. and L. A. W. (2007). The Critical Classroom: Education for Liberation and Movement Building. Project South.

Kirsch, I., Braun, H., Yamamoto, K., \& Sum, A. (2007). America's perfect storm - three forces changing our nation's future (pp. 1 - 34). Princeton, NJ: ETS. 
Kuh, G. (2008). High-Impact Educational Practices: What They Are, Who Has Access to Them, and Why They Matter on the LEAP Campus Toolkit. LEAP Campus Toolkit. Retrieved April 14, 2012, from http://leap.aacu.org/toolkit/high-impactpractices/2011/high-impact-educational-practices-what-they-are-who-has-accessto-them-and-why-they-matter

Ladson-Billings, G. (1995). But That's Just Good Teaching! The Case for Culturally Relevant Pedagogy. Theory into Practice, 34(3), 159-65.

Ladson-Billings, G. (2009). The Dreamkeepers: Successful Teachers of African American Children (2nd ed.). Jossey-Bass.

Lave, J., \& Wenger, E. (1991). Situated Learning: Legitimate Peripheral Participation (1st ed.). Cambridge University Press.

Leana, C. R. (2006). Social capital and organizational performance: Evidence from urban public schools. Organization Science, 17(3), 353. doi:10.1287/orsc.1060.0191

Levine, J. H., \& Shapiro, N. S. (1999). Creating Learning Communities: A Practical Guide to Winning Support, Organizing for Change, and Implementing Programs (1st ed.). Jossey-Bass.

Lieberman, A., \& Pointer Mace, D. H. (2008). Teacher Learning: the Key to Educational Reform. Journal of Teacher Education, 59(3), 226-234.

doi:10.1177/0022487108317020 
Little, J. W. (1993). Teachers' Professional Development in a Climate of Educational Reform. Educational Evaluation and Policy Analysis, 15(2), 129 -151. doi:10.3102/01623737015002129

Lorde, A. (2007). Sister Outsider: Essays and Speeches. Crossing Press.

Major, C. H., \& Palmer, B. (2006). Reshaping Teaching and Learning: The Transformation of Faculty Pedagogical Content Knowledge. Higher Education, 51(4), 619-647.

McLaughlin, M., \& Talbert, J. (2003). Reforming districts: how districts support school reform (pp. 1 - 40). Seattle, WA: Center for the Study of Teaching and Policy.

Meiklejohn, A. (2000). The Experimental College. UW-Madison Libraries Parallel Press.

Mezirow, J. (1997). Transformative learning: Theory to practice. New directions for adult and continuing education, 1997(74), 5-12.

Minh-Ha, T. T. (2009). Woman, Native, Other: Writing Postcoloniality and Feminism (1St ed.). Indiana University Press.

Minkler, M., Wallerstein, N., \& Hall, B. (2002). Community-Based Participatory Research for Health (1st ed.). Jossey-Bass.

Moore, C., \& Shulock, N. (2006). State of decline? Gaps in college access and achievement call for renewed commitment to educating Californians. Sacramento, CA: Institute for Higher Education Leadership and Policy.

Nieto, S. (2003). Affirming Diversity: The Sociopolitical Context of Multicultural Education, Fourth Edition (4th ed.). Allyn \& Bacon. 
O'Banion, T. (1997). A Learning College for the 21st Century. Greenwood Publishing Group.

Oakes, J., \& Lipton, M. (2002). Teaching To Change The World (2nd ed.). McGraw-Hill Humanities/Social Sciences/Languages.

Palmer, P. J. (1997). The Courage to Teach: Exploring the Inner Landscape of a Teacher's Life (1st ed.). Jossey-Bass.

Pascarella, E. T., \& Terenzini, P. T. (1991). How College Affects Students: Findings and Insights from Twenty Years of Research (1st ed.). Jossey-Bass.

Petrone, M. C. (2004). Supporting diversity with faculty learning communities: Teaching and learning across boundaries. New Directions for Teaching and Learning, 2004(97), 111-125. doi:10.1002/tl.138

Putnam, R. D. (1995). Bowling alone: America's declining social capital. The City Reader, , 120-128.

Shor, I. (1992). Empowering Education: Critical Teaching for Social Change (1st ed.). University Of Chicago Press.

Shor, I., \& Freire, P. (1986). A Pedagogy for Liberation. Bergin \& Garvey.

Shulman, L. S. (1986). Those who understand: Knowledge growth in teaching. Educational researcher, 15(2), 4-14.

Sleeter, C. E. (2005). Un-Standardizing Curriculum: Multicultural Teaching in the Standards-based Classroom (Multicultural Education. Teachers College Press. 
Sorcinelli, M. D. (1992). Developing New and Junior Faculty. (A. E. Austin, Ed.). Jossey-Bass Inc Pub.

Spivak, G. C. (1988). In other worlds: Essays in cultural politics. New York: Routledge.

Vygotsky, L. (1978). Mind in society. Cambridge, MAL Harvard University Press.

Yonezawa, S., Jones, M., \& Singer, N. R. (2011). Teacher Resilience in Urban Schools:

The Importance of Technical Knowledge, Professional Community, and Leadership Opportunities. Urban Education, 46(5), 913-931.

doi:10.1177/0042085911400341 
Appendix A: One-on-one interview protocol (faculty)

Sample Interview Questions

Teaching career and philosophy

1. Please start by telling me about your trajectory towards teaching. When did you first enter education as an instructor?

a. What would you say was your philosophy of teaching when you first started? What influenced this philosophy?

b. What are some of the expectations you have for yourself as a teacher? How did you develop these?

2. How has that philosophy shifted over the years? What are some things that influenced your teaching philosophy over the last ten years? The last five years? The last year?

a. What courses have you taught over the last three years? Do you have a favorite? Please explain.

b. Which course do you teach for the Metro program? How has this course changed over time? What do you do in the course now that you did not do when you first taught it?

\section{Teaching practice}

1. How much time do you spend on your teaching and planning in a week?

2. What would you say engages you most about your teaching?

a. How important is it to you to address issues of oppression and structures of resiliency in your classroom? Please explain.

b. How do issues of power play out in your classroom? Please describe in detail. 
c. How important is it to you to make your curriculum relevant for your students? Please explain.

3. What types of professional development have you received to assist you in thinking about some of the issues raised in the above questions? Please be as specific as possible.

\section{Impact of FLC on teaching practice}

1. Please describe the faculty learning community you participated in as a part of Metro.

2. How important is a community to you when examining your teaching practice? Explain.

3. What has been your experience in your institution of working in a community of faculty to change teaching practice?

a. What types of things within your own teaching practice, do you feel have changed as a result of participation in the faculty learning community?

b. Has participation in the Metro faculty learning community affected your thinking about pedagogy and relevant curriculum? If so, how? If not, why don't you think it has?

c. What specific skills, readings etc. have stood out for you? Have they affected you as a teacher? If so, how?

d. What role has incentives for participation played in keeping you coming to the FLC meetings?

4. Any final thoughts you would like to share with me before we end this interview?

Thank you very much for your time! 
Appendix B: Faculty Demographic Survey

Name

\section{Faculty Demographic Questionnaire}

Instructions: Please complete the questions marking an " $X$ " in the appropriate box or fill in the blank, to the best of your ability

1. What institution do you currently spend the majority of your time?

\section{$\square \operatorname{CCSF} \square$ SF STATE}

2. How many years have you been teaching at your current institution?

3. How many courses do you teach in a semester, on average?

4. Please mark the box that best describes your job description at the institution you checked in question \# 1.

\begin{tabular}{|l|l|}
\hline$\square$ & Part-time faculty with 2 courses or less \\
\hline$\square$ & Part-time faculty with 3 courses or more \\
\hline$\square$ & Full-time faculty, not tenure-track \\
\hline$\square$ & Full-time faculty, on tenure-track \\
\hline$\square$ & Full-time faculty, tenured \\
\hline
\end{tabular}

5. How do you describe your sex or gender?

\begin{tabular}{|l|l|}
\hline$\square$ & Male \\
\hline$\square$ & Female \\
\hline
\end{tabular}

6. Do you speak a language other than English?

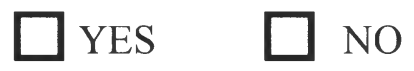

If you checked "yes" for question \# 6, please enter the language(s) below

7. How do you describe your race or ethnicity? Please check all that apply.

If you do not feel like these categories adequately represent you, please fill in your race/ethnicity

\begin{tabular}{||l|l|}
\hline$\square$ & Black/African American \\
\hline$\square$ & Hispanic/Latino/a \\
\hline$\square$ & Pacific Islander \\
\hline$\square$ & East Asian \\
\hline$\square$ & South Asian \\
\hline$\square$ & Filipino/a \\
\hline$\square$ & Native American \\
\hline$\square$ & White \\
\hline$\square$ & Decline to State \\
\hline
\end{tabular}


8. How many years have you been involved with the Metro Academies program?

9. How satisfied are you with your participation in the Metro Academies faculty learning community?

$\square$ Very satisfied $\square$ Satisfied $\square$ Very Dissatisfied

$\square$ Dissatisfied $\square$ Neither satisfied nor dissatisfied

10. How important are the following in your attendance and participation in the FLC meetings?

a. Payment for meeting attendance

$\square$ Important

$\square$ Do not have an impact

$\square$ Not Important

b. Feeling of community with participants

$\square$ Important
$\square$ Do not have an impact
$\square$ Not Important

c. Learning new teaching techniques

$\square$ Important

$\square$ Do not have an impact

$\square$ Not Important

d. Having conversations about teaching

$\square$ Important
$\square$ Do not have an impact
$\square$ Not Important

e. Reflecting on my own teaching practice

$\square$ Important

Do not have an impact

Not Important
11. What is the highest level of formal education achieved by your mother?

\begin{tabular}{|l|l|}
\hline$\square$ & Junior high/Middle school or less \\
\hline$\square$ & Some high school \\
\hline$\square$ & High school graduate or GED \\
\hline$\square$ & Some college, did not complete degree \\
\hline$\square$ & $\begin{array}{l}\text { College degree } \\
\text { (Associate's and/or Bachelor's) }\end{array}$ \\
\hline$\square$ & Some graduate school \\
\hline$\square$ & $\begin{array}{l}\text { Graduate degree } \\
\text { (Master's, JD, MD, Doctorate) }\end{array}$ \\
\hline$\square$ & \begin{tabular}{l} 
I don't know \\
\hline
\end{tabular} \\
\hline
\end{tabular}

12. What is the highest level of formal education achieved by your father?

\begin{tabular}{|l|l|}
\hline$\square$ & Junior high/Middle school or less \\
\hline$\square$ & Some high school \\
\hline$\square$ & High school graduate or GED \\
\hline$\square$ & Some college, did not complete degree \\
\hline$\square$ & $\begin{array}{l}\text { College degree } \\
\text { (Associate's and/or Bachelor's) }\end{array}$ \\
\hline$\square$ & Some graduate school \\
\hline$\square$ & $\begin{array}{l}\text { Graduate degree } \\
\text { (Master's, JD, MD, Doctorate) }\end{array}$ \\
\hline$\square$ & I don't know \\
\hline
\end{tabular}

Thank you very much for completing this questionnaire! 
Appendix C: Sample advisory group meeting agenda

\section{FLC Dissertation Advisory Group Meeting \\ November 1, 2011 \\ 7:00 pm to 9:00 pm at SFSU HSS 301}

\section{Desired Objectives}

- Develop community among Metro faculty and students

- Talk through how to set up research and work with student representatives to set up their own research questions

Agenda

\begin{tabular}{|l|c|}
\hline \multicolumn{1}{|c|}{ Topic } & Time Allotted \\
\hline $\begin{array}{l}\text { Get to know you activity + Welcome + Get food } \\
\text { Check in around the semester; how are things going for } \\
\text { everyone? }\end{array}$ & $7: 00$ to $7: 10 \mathrm{pm}$ \\
\hline Using Atlas. Ti & $7: 10$ to 7:50 pm \\
1) Purpose of using the software for qualitative analysis \\
2) General initial findings
\end{tabular}

Participants:

Herman Bormann

Cynthia Fong

Arai Buendia

Ann Marie Davidsen

Edgar Velazquez

Amy Conley Wright 
Appendix D: Sample advisory group meeting notes

\section{FLC Dissertation Advisory Group Meeting November 1, 2011 7:00 pm to 9:00 pm at SFSU HSS 301}

\section{Desired Objectives}

- Develop community among Metro faculty and students

- Talk through how to set up research and work with student representatives to set up their own research questions

\section{Agenda}

\begin{tabular}{|c|c|}
\hline Topic & Time Allotted \\
\hline $\begin{array}{l}\text { Get to know you activity + Welcome + Get food } \\
\text { Check in around the semester; how are things going for everyone? } \\
\text { Folks felt like things were difficult at this point. Everyone felt tired and a little } \\
\text { worn out from all of the work. For the students, it felt overwhelming to try and } \\
\text { balance all the different aspects of life and school and for the faculty, this time } \\
\text { seemed difficult with the grading and demands of the institution. }\end{array}$ & $7: 00$ to $7: 10 \mathrm{pm}$ \\
\hline $\begin{array}{l}\text { Using Atlas. Ti (led by Amy Conley) } \\
\text { Mini-lesson on qualitative data analysis } \\
\text { Amy described the purpose of using the software as a tool for analysis, but } \\
\text { does not replace the mind or critical thinking of the researcher and her team. It } \\
\text { is a way to organize and pull important quotes from the data without having to } \\
\text { do all of that by hand. }\end{array}$ & \\
\hline $\begin{array}{l}\text { Purpose of coding data: to reduce the complexity; distill larger amounts of data } \\
\text { into more manageable chunks } \\
\text { - Inductive coding: codes you put on the data; usually comes from theory } \\
\text { or research } \\
\text { Deductive coding: codes you pull from the data after combing through } \\
\text { it a few times (ideally) }\end{array}$ & $7: 10$ to $7: 50 \mathrm{pm}$ \\
\hline
\end{tabular}


We then spent a bit of time working with an actual transcript from a one-onone interview that I conducted with one of our faculty members. We each read through the transcript silently (pages $4 \& 5$, to give us a digestible chunk) and marked codes based on a bit of theory as well as created our own deductive codes.

Codes (that came from a quick run of theoretical constructs)

1) Ability to reflect impacts teaching

2) Preference for reflection in community

3) FLC creates a sense of connection with colleagues and with campus

We created the table collectively on the white board with Amy's direction. A few of us shared out our quotes that we highlighted and we came up with codes together.

\begin{tabular}{|l|l|}
\hline \multicolumn{1}{|c|}{ Codes } & \multicolumn{1}{c|}{ Quotes } \\
\hline $2 \& 3$ (see above) & "Being in Metro...higher ed" \\
\hline Teaching & "When I started..." \\
\hline 1, teaching and self-evaluation & "So when I am..." \\
\hline
\end{tabular}

You can also create families of codes, where more than one can be classified in a larger way to include smaller codes.

Using Atlas.Ti software instructions

1) Create a new hermanutic unit

2) Assign documents to that unit

3) Highlight something that you want to code

4) Codes can be added as a free code- $\rightarrow$ Type the code and press ok

5) Quotation manager $\rightarrow$ can create a document with quotes on reflection

6) Create memos $\rightarrow$ this is a way to capture thoughts or reflections

\section{Talk about next steps and set up future meetings}

Cynthia and Amy were happy to lead the workshop on Atlas.Ti, but would like to be more involved with the data once we have a list of codes that we are working with.

The students, Herman, Ann Marie, Arai and Edgar wanted to be more involved with analysis from the ground. We discussed how that could happen and 
agreed upon the students taking 2-3 transcripts per person and would code them by hand using deductive coding. They wanted me to do my own coding as well and then we would meet again in early January to discuss the list of codes and do more detailed analysis together as a large advisory group.

I need to schedule a meeting in December with the students to further their research idea and to give them cleaned up transcripts to look at and code. I also need to schedule an advisory group meeting in January with the entire group.

\section{Honing the research question}

Have students talk about the research project and work on narrowing the question; begin talking about methods

The student group welcomed Herman into their research and talked about narrowing the research question to: What types of stressors do upper division college students at SF State have that affect their weight?

Sub-question: How does major choice impact weight?

The students were adamant that they look at an issue they see on campus, which is the rise in overweight among their peers. They want to look at some of the risk factors or causes, including

Gender

Socioeconomic status

Ethnicity

This was a preliminary list, which will continue to be built out at the next meeting. Ann Marie has a connection with someone in the student health services, who want this information to target their outreach to college students better around healthy eating and exercise. We will follow up with this contact to see if this data can be collected and used in her group.

There was also excitement around each of them being able to write about different aspects of the issue from their own individual lenses. Edgar can write from a medical perspective, Herman from a social work perspective and Arai and Ann Marie from a public health perspective. Students remarked at the end of the meeting that they felt tired coming into the meeting, but were reenergized and revitalized afterward. 


\section{Conducting interviews}

$8: 40$ to $9: 00 \mathrm{pm}$

Set up a time with the students to have them interview me about my role as FLC. This can also serve as practice run for their own data collection

Students will do this during our December regroup.

Participants:

Herman Bormann

Cynthia Fong

Arai Buendia

Edgar Velazquez

Ann Marie Davidsen

Amy Conley Wright 